\title{
Article \\ Ultrafine Jujube Powder Enhances the Infiltration of Immune Cells during Anti-PD-L1 Treatment against Murine Colon Adenocarcinoma
}

\author{
Nan Jing ${ }^{1,2}\left(\mathbb{D}\right.$, Luoyang Wang $^{3}$, Huiren Zhuang ${ }^{1,2}\left(\mathbb{D}\right.$, Guoqiang Jiang ${ }^{1,2, *}$ and Zheng Liu ${ }^{1,2, *(\mathbb{D})}$ \\ 1 Key Lab of Industrial Biocatalysis Ministry of Education, Tsinghua University, Beijing 100084, China; \\ jn17@mails.tsinghua.edu.cn (N.J.); zhuanghr19@mails.tsinghua.edu.cn (H.Z.) \\ 2 Department of Chemical Engineering, Tsinghua University, Beijing 100084, China \\ 3 School of Basic Medicine, Qingdao University, Qingdao 266071, China; wangnan235@qdu.edu.cn \\ * Correspondence: jianggq@tsinghua.edu.cn (G.J.); liuzheng@mail.tsinghua.edu.cn (Z.L.); \\ Tel.: +86-010-62779876 (Z.L.)
}

Citation: Jing, N.; Wang, L.; Zhuang, H.; Jiang, G.; Liu, Z. Ultrafine Jujube Powder Enhances the Infiltration of Immune Cells during Anti-PD-L1 Treatment against Murine Colon Adenocarcinoma. Cancers 2021, 13, 3987. https://doi.org/10.3390/ cancers13163987

Academic Editor: Sandra Gessani

Received: 1 June 2021

Accepted: 5 August 2021

Published: 7 August 2021

Publisher's Note: MDPI stays neutral with regard to jurisdictional claims in published maps and institutional affiliations.

Copyright: (c) 2021 by the authors. Licensee MDPI, Basel, Switzerland. This article is an open access article distributed under the terms and conditions of the Creative Commons Attribution (CC BY) license (https:/ / creativecommons.org/licenses/by/ $4.0 /)$.
Simple Summary: While modulating gut microbiota using dietary intervention with natural nutrients has proven to be effective in improving the response rate of immune checkpoint inhibitors (ICIs), the underpinning mechanism is poorly understood. This work demonstrates that the oral administration of ultrafine jujube powder (JP) let to a significant alteration of gut microbiota, an increased abundance of Clostridiales, including Ruminococcaceae and Lachnospiraceae, an elevated SCFA production, an intensified infiltration of $\mathrm{CD}^{+} \mathrm{T}$ cells to the tumor microenvironment, and a greatly improved response of anti-PD-L1 treatment against murine colon adenocarcinoma. Moreover, the size of the JP particles had a significant impact on the abovementioned attributes. The present study demonstrates that dietary intervention with nutrients is highly effective in modulating the gut microbiota for an improved immune checkpoint blockage therapy.

Abstract: Whereas dietary intervention with natural nutrients plays an important role in activating the immune response and holds unprecedented application potential, the underpinning mechanism is poorly understood. The present work was dedicated to comprehensively examine the effects of ultrafine jujube powder (JP) on the gut microbiota and, consequentially, the effects associated with the response rate to anti-PD-L1 treatment against murine colon adenocarcinoma. A murine colon adenocarcinoma model with anti-PD-L1 immunotherapy was established to evaluate how dietary interventions affect the microbiota. In vitro and in vivo experiments confirmed the role of SCFAs in the immune response. Oral administration of JP greatly improves the response of antiPD-L1 treatment against murine colon adenocarcinoma. Such an improvement is associated with the alteration of gut microbiota which leads to an increased abundance of Clostridiales, including Ruminococcaceae and Lachnospiraceae, an elevated SCFA production, and an intensified infiltration of $\mathrm{CD}^{+} \mathrm{T}$ cells to the tumor microenvironment. This work demonstrates that JP is particularly effective in modulating the gut microbiota for an improved immune checkpoint blockage therapy by boosting cytotoxic $\mathrm{CD}^{+} \mathrm{T}$ cells in tumor-infiltrating lymphocytes. The experimental findings of the present study are helpful for the development of dietary intervention methods for cancer immunotherapy using natural nutrients.

Keywords: immune checkpoint inhibitors; colon adenocarcinoma; dietary intervention; short-chain fatty acids (SCFAs); tumor-infiltrating lymphocytes

\section{Introduction}

While immune checkpoint inhibitors (ICIs) targeting programmed cell death ligand 1 (PD-1) or cytotoxic T lymphocyte-associated protein-4 (CTLA-4) have achieved tumor regression in several cancers [1,2], the unexpected low response rate, typically below 
$30 \%$, hinders the full display of this revolutionary procedure [3]. Recent years have witnessed ever growing efforts in modulating the gut microbiome for improving responses to ICIs [4-9], through a wide variety of innovative strategies such as dietary interventions [10], administration of bacterial consortia or "Designer Probiotics" [11], and fecal microbiota transplantation (FMT) [12].

Among them, dietary intervention is practically attractive due to its public acceptability, natural availability, and quick effect $[13,14]$. Various microbial communities are intimately involved in human digestion and nutrient extraction [15]. It has been well established that the increased abundance of pectin, inulin, and alike is conductive to an enhanced response to ICI treatment [16], whereas the administration of natural ingredients rich in dietary fibers is effective to modulate the gut microbiota to a favorable pattern. Jujube (Chinese date), scientifically known as Ziziphus jujuba Mill., is a natural fruit extensively applied to traditional Chinese Medicine. Jujube delivers significant nutritional and medicinal values $[17,18]$, such as antioxidant and anti-inflammatory effects [19], antimicrobial activity [20], anticancer properties [21], immunostimulating properties [22-24], and gastrointestinal protective activity [25]. In previous work, we demonstrated that the oral admission of jujube enriched the abundance of Lachnospiraceae while it reduced that of Prevotellaceae, thereby improving the therapeutic efficiency and response rate of anti-PD-L1 against murine colon adenocarcinoma [26].

The beneficial effects of natural nutrients may derive from the fermentation of dietary fibers into bioactive metabolites [27] that impact local and systemic immune responses [28], including the $\mathrm{CD} 8^{+} \mathrm{T}$ cell responses [29]. Jian and coworkers [30] confirmed that L. murinus is associated with the activation of intestinal DCs while B. uniformis displays the strongest positive correlation with the proportion of IFN $\gamma^{+} \mathrm{CD}^{+} \mathrm{T}$ cells in mesenteric lymph nodes (MLNs) in mice, which can trigger an antitumor immune response. Honda and coworkers [31] found that the abundance of Bifidobacterium is positively correlated with intratumoral and peripheral $\mathrm{CD} 8^{+} \mathrm{T}$ cell responses. Moreover, it has been shown that 11 specific bacterial strains from healthy donor stools could accumulate and recruit intestinal IFN $\gamma^{+} \mathrm{CD}^{+} \mathrm{T}$ cells [31]. McCoy and coworkers [32] confirmed that Bifidobacterium pseudolongum and Lactobacillus johnsonii could significantly enhance the CD8 ${ }^{+} \mathrm{T}$ cell responses in the tumor microenvironment (TME) consistent with the improved efficacy of anti-PD-L1 and anti-CTLA-4 therapy on colorectal cancer.

High concentrations of fecal or plasma SCFAs have been associated with better responses to PD-1 treatment and longer progression-free survival [33]. SCFAs play a vital role in communication between the gut microbiota and the mucosal immune system [34]. In animal studies, SCFAs have been shown to influence intestinal adaptive immune responses through regulating the size and function of the regulatory T-cell pool [35]. SCFAs can also amplify the cytotoxicity of $\mathrm{CD} 8^{+} \mathrm{T}$ cells through cellular metabolism, which further maintains a balance between innate and adaptive immunity [29].

This enhancement can be achieved by using natural nutrients (e.g., jujube powder) through nurturing the gut microbiota, simulating SCFAs, and enhancing infiltration of immune cells to the microenvironment of the tumor cell. Moreover, we conjecture that the infiltration efficiency can be enhanced by tuning both food composition and morphology.

The Chinese classical medical books "The Theory of Food" (Shi Lun) by Hua Tuo and "Thousand Golden Preions" (Qian Jin Yao Fang) by Sun Simiao both recommended to "chew carefully and swallow slowly" so as to physically disrupt food as completely as possible. It is generally recognized that the most important impact of particle size on nutrition is the release and intestinal absorption of nutrients in the food. For instance, the hydration and other physicochemical properties of cellulose can be improved by reducing the size [36,37]. Meanwhile, growing evidence indicates that the nutritional value of food is not limited to the solubilized parts; it includes also those insolubilized components that can be used by gut microbes. Given the aforementioned findings, we hypothesize that the improved efficiency of anti-PD-L1 against murine colon adenocarcinoma attained with the aid of a favorable gut microbiota might be associated with an increased infiltration of 
immune cells in the TME. Moreover, we conjecture that the infiltration efficiency can be enhanced by tuning both the food composition and morphology. Here, we examined the effects of the size of JP particles on the metabolism of SCFAs, the composition of intestinal flora, and the infiltration of immune cells. We started with the investigation of the JP size effect on mice gut microbiota. We examined the JP particles in terms of the surface properties such as zeta potential, morphology, and aggregation. We applied JP in the antiPD-L1 treatment against murine colon adenocarcinoma and determined the concentration of SCFAs, as well as the infiltration of $\mathrm{CD}^{+}$and $\mathrm{CD} 8^{+} \mathrm{INF} \gamma^{+}$in the microenvironment of tumor cells. These investigations allowed us to establish a comprehensive description of the underlying mechanism of JP in terms of the response rate to anti-PD-L1 treatment.

\section{Materials and Methods}

\subsection{Materials}

Ziziphus jujuba cv. Junzao was purchased from Akesu, Xinjiang, China. In vivo MAb anti-mouse PD-L1 (B7-H1) and immunoglobulin G (IgG, BE0090) were obtained from BioXCell (West Lebanon, NH, USA). All antibodies were bought from eBioscience (San Diego, CA, USA). Heat-resistant amylase, protease, and amyloglucosidase were purchased from Sigma-Aldrich (St. Louis, MO, USA). Reagents for cell culture were purchased from Gibco (Grand Island, NY, USA). Acetate, propionate, butyrate, and valerate were purchased from Macklin (Shanghai, China). All other chemicals and reagents were analytical grade, unless otherwise specified.

\subsection{Preparation of Jujube Powders}

Ziziphus jujuba cv. Junzao fruits were cleaned, sliced, and air-dried at $50{ }^{\circ} \mathrm{C}$ for $24 \mathrm{~h}$, followed by coarse grinding using a pulverizer and sieving through a 100 mesh sieve, yielding jujube powder denoted as $P$. The ultrafine ground jujube powder was prepared at ultra-low temperature using an ultrafine grinder PLS-10L (Jinan Preshen Machinery Equipment Co., Ltd., Jinan, China), and then sieved through 200 mesh, 270 mesh, and 800 mesh sieves, yielding ultrafine powders denoted as S1, S2, and S3. All jujube powders were stored at $-20^{\circ} \mathrm{C}$ until analyzed.

\subsection{Analysis of Particle Size and Surface Properties of Jujube Powders}

The morphology of jujube powders was monitored using a JSM7401 scanning electron microscope (SEM) (JEOL, Tokyo, Japan). Zeta potential and particle size distribution were determined by dynamic light scattering (DLS) using a Mastersizer 3000 (Malvern instrument Ltd., Worcestershire, UK). Surface groups and chemical properties of jujube powders were determined with Fourier-transform infrared spectroscopy (FTIR) (Nicolet 6700FTIR, Thermo Scientific, Waltham, USA). The water content was determined with differential scanning calorimetry (DSC) (Q5000IR, TA Instruments, New Castle, PA, USA) in $\mathrm{N}_{2}$ atmosphere at a flow rate of $50 \mathrm{~mL} / \mathrm{min}$, whereas the temperature range was from 25 to $300{ }^{\circ} \mathrm{C}$ at a heating rate of $20{ }^{\circ} \mathrm{C} / \mathrm{min}$, with an aluminum crucible as the reference. The rose Bengal staining method was used to detect the hydrophobicity of JP. Certain amounts (1-5 mg/mL) of JP and Bangladesh rose (RB, $10 \mu \mathrm{g} / \mathrm{mL}$ ) were added to deionized water and stirred for $24 \mathrm{~h}\left(37^{\circ} \mathrm{C}, 100 \mathrm{rpm}\right)$. The concentration of supernatant was measured at $542.7 \mathrm{~nm}$. The partitioning quotient (PQ) of RB was calculated according to the following formula: $\mathrm{PQ}=\frac{\text { mass of } \mathrm{RB} \text { on JP surface }}{\text { mass of } \mathrm{RB} \text { in aqueous phase }} \times 100 \%$. Linear fitting was carried out with the content of JP as the abscissa and PQ as the ordinate. Therefore, the slope K was the adsorption rate of RB on the surface of JP, which increased with the magnitude of hydrophobicity.

\subsection{Analysis of Dietary Fiber}

The enzymatic-gravimetric method was used to determine the contents of total dietary fiber (TDF), soluble dietary fiber (SDF), and insoluble dietary fiber (IDF) in jujube powders according to the Association of Official Analytical Chemists (AOAC, 2002). Briefly, all 
samples were successively digested with amylase, protease, and amyloglucosidase to remove protein and starch. Specific experimental methods were based on AOAC with minor modifications [38].

\subsection{Animals and Treatments}

All mice used in experiments were 7 week old female C57BL/6 mice (Vital River Laboratory Animal Technology Co., Ltd., Beijing, China) housed under specific pathogenfree conditions according to the protocols approved by the Institutional Animal Care and Use Committees of Tsinghua University for animal welfare (approval ID SYXK2019-0037).

The mouse model of colon cancer was established by subcutaneously inoculating mice with $5 \times 10^{5} \mathrm{MC} 38$ cells at the right flank after 1 week of adaptation. Tumor volumes $\left(\right.$ width $^{2} \times$ length) $/ 2$ ) were measured twice a week. Seven days after tumor inoculation, mice were divided into different groups of six mice with randomized tumor size. For the $\alpha$ PD-L1-treated groups ( $\alpha$ PD-L1), mice received $200 \mu \mathrm{g}$ of $\alpha$ PD-L1 by intraperitoneal injection twice on days 7 and 10. The isotype control group (CTR) mice received IgG at the same time. For groups treated with $\mathrm{P}, \mathrm{S} 1, \mathrm{~S} 2$, and S3, mice were gavaged with a dose of $800 \mathrm{mg} / \mathrm{kg}$ jujube powder daily from day 7 to day 25, following previous studies $[39,40]$. For the group treated with butyrate, butyrate at a dose of $80 \mathrm{mM}$ was added to drinking water from day 7 to day 25. All mice were euthanized on day 25 for data analysis. MC38 cells were obtained from the American Type Culture Collection and were cultured in DMEM culture medium supplemented with $10 \%$ fetal bovine serum (FBS) and $1 \%$ penicillin-streptomycin at $37^{\circ} \mathrm{C}$ in $5 \% \mathrm{CO}_{2}$ atmosphere.

For short-chain fatty acid (SCFA) experiments, healthy mice were randomly divided into different groups of six mice after 1 week of adaptation. Acetate $(\mathrm{C} 2)$, propionate (C3), and butyrate (C4) at a dose of $80 \mathrm{mM}$ and mixtures of SCFAs (C2, C3, and C4 at a dose of $40 \mathrm{mM}$ ) were added to drinking water for 1 week. For microbial diversity and RNA-sequencing analysis, healthy mice were randomly divided into different groups of six mice after 1 week of adaptation and gavaged with $\mathrm{P}, \mathrm{S1}, \mathrm{S} 2$, or S3 at a dose of $800 \mathrm{mg} / \mathrm{kg}$ daily for 1 week. Eventually, all mice were euthanized on day 7 for data analysis.

\subsection{Lymphocyte Culture In Vitro and Proliferation Assay}

The experimental methods were according to Cavaglieri with slight adjustment [41]. Briefly, mesenteric lymph nodes were isolated from healthy mice and prepared into a singlecell suspension with RPMI culture medium containing 10\% FBS, 2 mM glutamine, and 1\% penicillin-streptomycin. Lymphocytes $\left(5 \times 10^{5}\right)$ were cultured in 96-well round-bottom culture plates. SCFAs (final concentration acetate (C2) $1 \mathrm{mM}$, propionate (C3) $1 \mathrm{mM}$, and butyrate (C4) $1 \mathrm{mM}$ ) and T cell mitogen Con A (final concentration $5 \mu \mathrm{g} / \mathrm{mL}$ ) were added and then the final volume was adjusted to $200 \mu \mathrm{L}$ for incubation $\left(37^{\circ} \mathrm{C}, 5 \% \mathrm{CO}_{2}\right)$. After $24 \mathrm{~h}$ or $48 \mathrm{~h}$, the cells were then harvested for analysis of CD8 ${ }^{+}$and CD4 ${ }^{+} \mathrm{T}$ cells by FACS.

\subsection{Analysis of Fecal Short-Chain Fatty Acids (SCFAs)}

Gas chromatography (GC-2010, Shimadzu, Kyoto, Japan) was used to detect the content of SCFAs [42]. Briefly, $0.1 \mathrm{~g}$ of fecal samples were suspended in $0.5 \mathrm{~mL}$ of dilute sulfuric acid $\left(\mathrm{H}_{2} \mathrm{O}: 50 \% \mathrm{H}_{2} \mathrm{SO}_{4}=4: 1, v / v\right)$. After homogenization (5 min) and centrifugation $(13,000 \times g, 10 \mathrm{~min})$, the supernatant was extracted with ethyl ether of equal volume for analysis. Chromatographic analysis conditions were consistent with those described previously [42].

\subsection{Detection of Immune Cells in Tumor and Spleen by FACS}

The surface marker expression in tumors was analyzed according to the literature [43]. In brief, the tumor and intestinal lamina propria were minced and digested in HBSS with Collagenase IV (Yeasen Biotech Co., Ltd., Shanghai, China) at $37^{\circ} \mathrm{C}$ for $1 \mathrm{~h}$. A $70 \mu \mathrm{m}$ cell strainer (BD Biosciences) was used to obtain the single cells through filtering digested tissues. For immune cells from the spleen and mesenteric lymph nodes (MLNs), the spleen 
was placed directly in a $70 \mu \mathrm{m}$ cell strainer, and then spleen tissues were gently ground to obtain the single cells using the plunger of a sterile syringe. The spleen cells were added to erythrocyte lysate on ice for $10 \mathrm{~min}$. Single cells were stained for $30 \mathrm{~min}$ in the dark at $4{ }^{\circ} \mathrm{C}$ with optimized concentrations of anti-mouse antibodies for CD4 (30-F11), CD8 (53-6.7), CD45 (GK1.5), CD25 (PC61.5), CD19 (1D3), and NK1.1 (PK136). For intracellular staining, cells were fixed and permeabilized with a Foxp3/Transcription Factor Staining Buffer Set (eBioscience) after surface staining, and then stained for $30 \mathrm{~min}$ in the dark at $4{ }^{\circ} \mathrm{C}$ with anti-mouse antibodies including Foxp3 (150D), IL-17 (eBio17B7), and IFN $\gamma$ (XMG1.2). After washing twice, cells were resuspended in the FACS buffer and measured using a FACS Calibur flow cytometer (BD Franklin Lakes, NJ, USA). The data were analyzed with the FlowJo software (Version 10.6.2, TreeStar, Inc., Ashland, OR, USA).

\subsection{Determination of Serum IgA and LPS}

Immunoglobulin A (IgA) and lipopolysaccharide (LPS) in serum were measured with the ELISA kits (Invitrogen, Carlsbad, CA, USA) according to the manufacturer' instructions.

\subsection{Analysis of Gut Microbiota}

We characterized the composition of the bacterial community in fecal samples using $16 S$ rRNA gene amplicon sequencing. After a 1 week treatment with jujube powder, feces of mice were collected, and the QIAamp DNA Stool Mini Kit (Qiagen, Germany) was applied to extract the genomic DNA according to the instructions of the manufacturer. PCR targeting the V3-V4 region of the 16S rRNA gene was executed, and subsequent amplicon sequencing was performed according to the standard protocols by Shanghai Majorbio Bio-Pharm Technology Co., Ltd. (Shanghai, China). as previously described [26]. The sequences of bacteria were uploaded to the NCBI Sequence Read Archive with accession number SUB9454167 (https:/ / www.ncbi.nlm.nih.gov/sra/SUB9454167) and it will be accessible after 1 May 2022.

\subsection{RNA-Sequencing and Data Analysis}

TRIzol ${ }^{\circledR}$ Reagent was applied for extraction of total RNA from the MLNs following the instructions of the manufacturer (Invitrogen). RNA-Seq analysis was performed with the Illumina HiSeq xten/NovaSeq 6000 sequencer $(2 \times 150$ bp read length) by Shanghai Majorbio Bio-Pharm Technology Co., Ltd. The reads were then processed and analyzed according to [44-46]. To identify the differences in gene expression, the transcripts per million reads (TPM) method was used to calculate the expression level of each transcript. Moreover, functional enrichment analysis was performed to identify significant differential genes in GO terms at a $p$-value $\leq 0.05$

\subsection{Bioinformatics Analysis}

The alpha diversity was analyzed using the online Majorbio I-Sanger Cloud Platform (www.i-sanger.com). The Euclidean distance was calculated using R package ade4 for betadiversity analysis, and the key OTUs (operational taxonomic units) which influence PCA clustering were extracted. BugBase was applied to predict the microbiome phenotypes. A co-occurrence network based on the spearman correlation matrix was constructed using the "WGCNA" R package [47]. OTUs with relative abundance $>0.1 \%$ were used here. The minimum module size was set to 20 , while the merge cut height was set to 0.25 . The soft threshold was used to ensure a scale-free network. Pearson's coefficient correlations were calculated to assess the relationships between the OTUs and the production of SCFAs. Permutation analysis of variance (PERMANOVA) using the adonis function in the vegan package with default settings was applied to evaluate community dissimilarity. Pairwise differences were calculated using the 'pairwise.perm.manova' function from the package RVAideMemoire. 


\subsection{Statistics}

We performed all statistical analysis using GraphPad Prism 8.0 (GraphPad Softioare Inc., San Diego, CA, USA). The two-tailed Student's $t$-test was used when comparing two groups, and one-way ANOVA was used when making multiple comparisons. All graphs show mean and error bars representing SEM; a $p$-value $<0.05$ was considered to be statistically significant, while a $p$-value $<0.01$ indicated high statistical significance $\left({ }^{*} p<0.05,{ }^{* *} p<0.01,{ }^{* * *} p<0.001\right.$, ns: not significant).

\section{Results}

\subsection{Surface Properties of Jujube Powders}

Figure 1A shows the SEM images of the jujube powders of different particle sizes. A complete surface was retained for sample $\mathrm{P}$, indicating the existence of original structures. Compared with sample $P$, major changes can be identified from the surface of ultrafine powders S1, S2, and S3, i.e., the lamellar structure at the surface almost disappeared and the original tissue structure was destroyed. When the particle size was below $10 \mu \mathrm{m}$, the internal structure was exposed, which enhanced interparticle attraction and, thus, particle agglomeration.

A
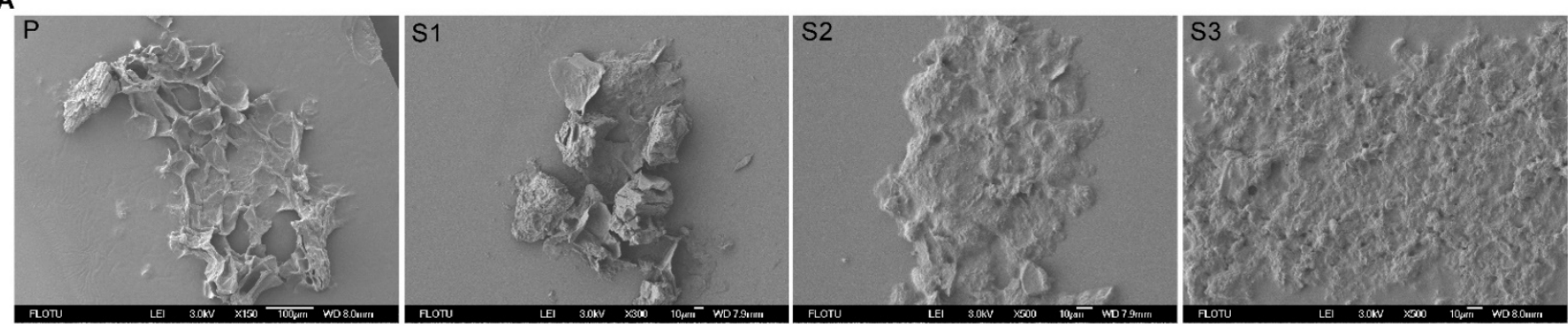

B
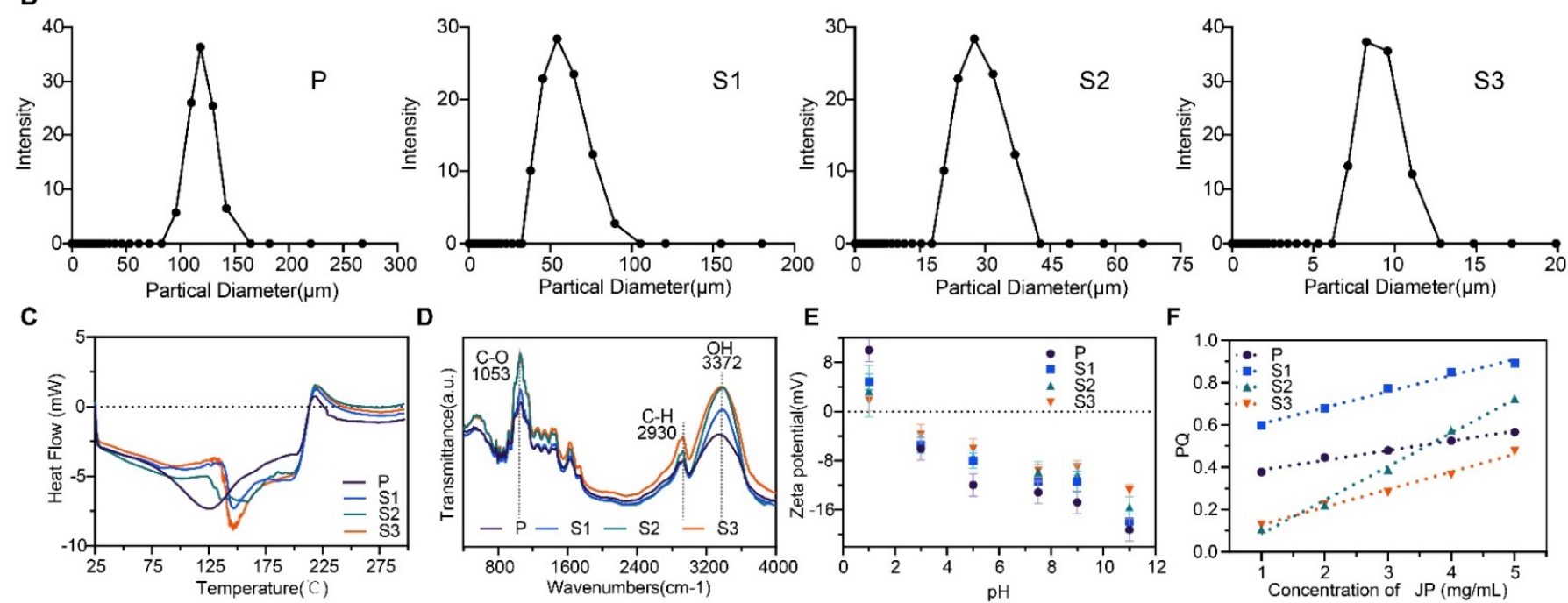

Figure 1. Morphological and surface properties of jujube powder characterized by (A) SEM micrographs, (B) particle size distributions, (C) DSC, (D) FTIR spectra, (E) zeta potential, and (F) hydrophobicity.

Figure 1B shows the size distribution of the jujube powders. Sample P exhibited the broadest Z-average size distribution with one peak occurring at $80-160 \mu \mathrm{m}$, whereas $\mathrm{S} 1$, S2, and S3 had average distributions of 40-110 $\mu \mathrm{m}, 15-45 \mu \mathrm{m}$, and 6-13 $\mu \mathrm{m}$, respectively. Accordingly, the Z-average sizes of samples P, S1, S2, and S3 were $137 \pm 39 \mu \mathrm{m}, 65 \pm 28$, $36 \pm 4$, and $9 \pm 0.6(\mu \mathrm{m})$, respectively. Figure $1 \mathrm{C}$ shows that all samples exhibited a similar DSC spectrum characterized by a distinct endothermic peak and one exothermic peak. Samples S1, S2, and S3 had a distinct heat absorption peak at $150{ }^{\circ} \mathrm{C}$, whereas the peak 
of the P sample was broadened and moved forward to $125^{\circ} \mathrm{C}$. This may be attributed to the endothermic effect caused by protein decomposition. One small exothermic peak at $225^{\circ} \mathrm{C}$ of all samples may be attributed to ash decomposition. Figure 1D shows that the FTIR spectra of all samples had an absorption peak at $3372 \mathrm{~cm}^{-1}$, which is the stretching vibration peak of $\mathrm{O}-\mathrm{H}$ in natural polysaccharides and phenols. The absorption peak near $290 \mathrm{~cm}^{-1}$ refers to the $\mathrm{C}-\mathrm{H}$ stretching vibration on $-\mathrm{CH} 2$ or $-\mathrm{CH} 3$ in polysaccharide compounds [38,48,49]. The absorption peak at $1053 \mathrm{~cm}^{-1}$ indicates the stretching vibration of $\mathrm{C}-\mathrm{O}$ from the carbohydrates, such as polysaccharides [50]. As shown in Figure 1E,F, the increase in the jujube powder particle size magnified the zeta potential but reduced the hydrophobicity. Table S1 presents the specific surface area, aqueous solubility, and water holding capacity (WHC) of the ultrafine powders in comparison with those corresponding to coarse powders. The results show apparent changes in the morphology and properties of jujube powder with different particle size.

\subsection{Changes in Gut Microbiota of Mice with Jujube Powder}

The gut microbiota communities of mice were characterized after 1 week administration of JP by $16 \mathrm{~S}$ rRNA gene sequencing covering the V3-V4 regions. As shown in Figure 2A, administration of S2 and S3 significantly increased the alpha-diversity index in terms of both microbial richness (Ace) and diversity (Shannon), as compared to the control group (CTR). The Simpson index also reflects the microbial richness. This index is the probability that two individuals chosen randomly from the community belong to identical species [51]. Therefore, a smaller Simpson index indicates greater microbial richness. The Simpson index decreased significantly in S2 and S3 treatment groups, which is consistent with the previous results. Beta diversity (Figure 2B), as interpreted from principal component analysis (PCA), revealed five separate clusters representing differential microbiotas. Permutational multivariate analysis of variance on Bray-Curtis dissimilarities confirmed the marked changes in the composition of microbiota $\left(R^{2}=0.313, p<0.001\right)$. Pairwise tests revealed significant changes in S1, S2, and S3 groups $(p<0.05)$, but not the P group when compared with the CTR group. Furthermore, it was found that six key OTUs (OTU752, OTU717, OTU235, OTU315, OTU780, and OTU177) significantly affected PCA clustering (Figure 2C). As can be seen from Figure 2D, these six core OTUs belong to two family levels: Muribaculaceae (OTU752, OTU717, OTU315, and OTU177) and Lachnospiraceae (OTU235 and OTU780). These results indicate that 1 week oral administration of jujube powder with different particle sizes can significantly change the diversity and structure of intestinal microorganisms in mice.

\subsection{Taxonomic Analysis of the Gut Microbiota}

We further analyzed the taxonomic composition at different levels of intestinal microorganisms. The ratio of Firmicutes to Bacteroidetes $(\mathrm{F} / \mathrm{B})$ increased as the particle size fell at the phylum level (Figure 3A). Consistently, microbiotas were differentially abundant in certain genera. All mice fed with JP had more Lachnospiraceae and Muribaculum but less Muribaculaceae and Rikenellaceae in the gut microbiota (Figure 3B). Moreover, these changes became more significant in the case of small JP particles. Figure $3 \mathrm{C}$ shows the specific differences between groups according to linear discriminant analysis (LDA) and effect size (LEfSe) analysis (LDA score is shown in Figure S3). The results agree well with those shown in Figure 3A,B, i.e., we observed a higher abundance of Lachnospiraceae, Lactobacillaceae, and Ruminococcaceae in mice after oral supplementation with S2 and S3 than in the CTR group. These results indicate that the reduction in particle size rendered jujube powder more effective to increase the population of beneficial microorganisms. 

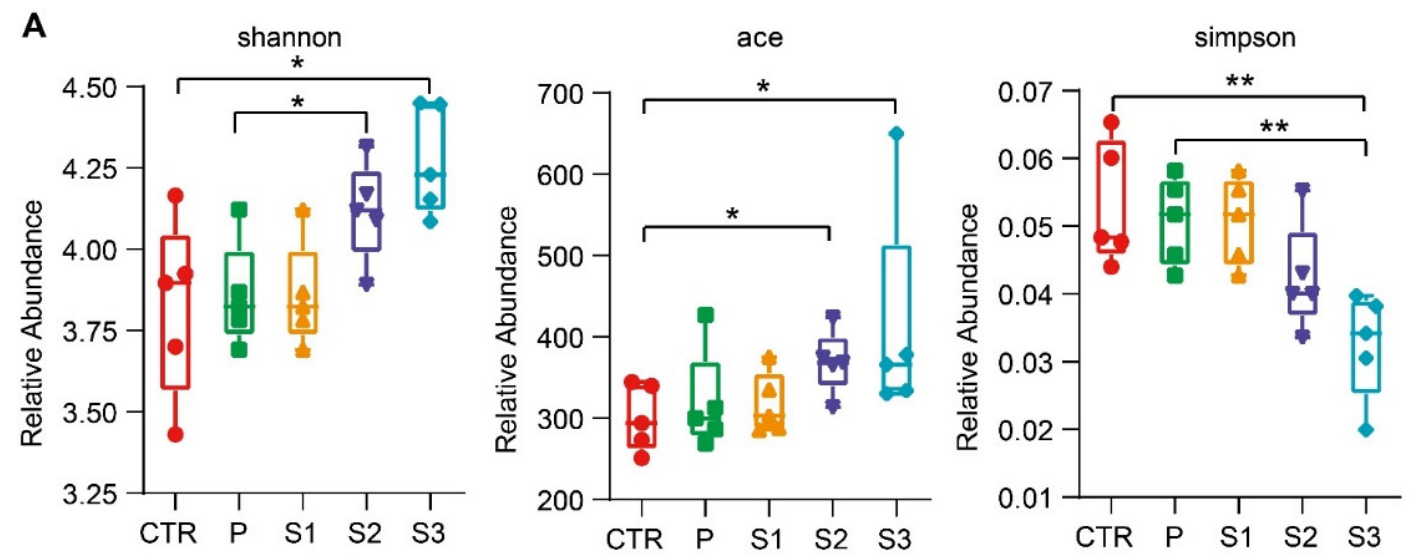

B

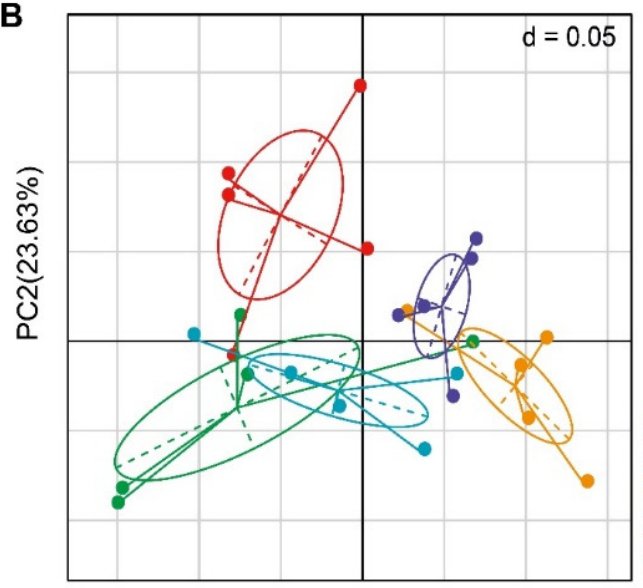

PC1 $(29.88 \%)$

C

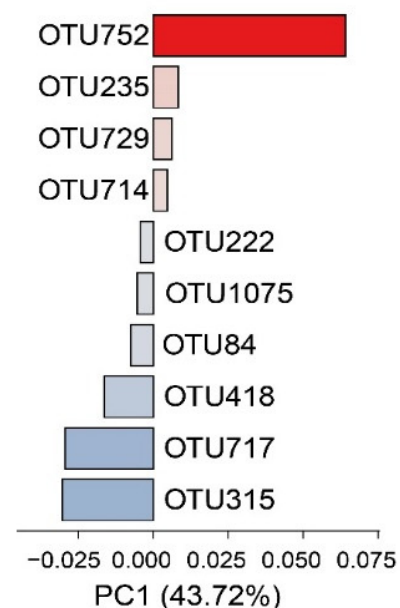

D

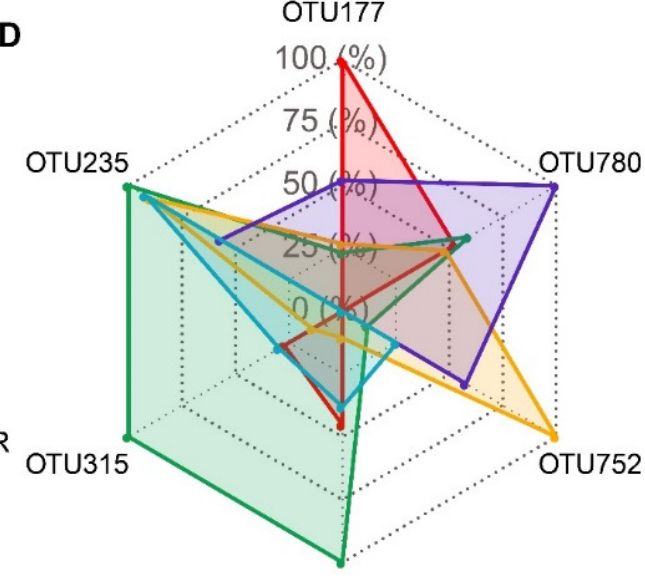

OTU717
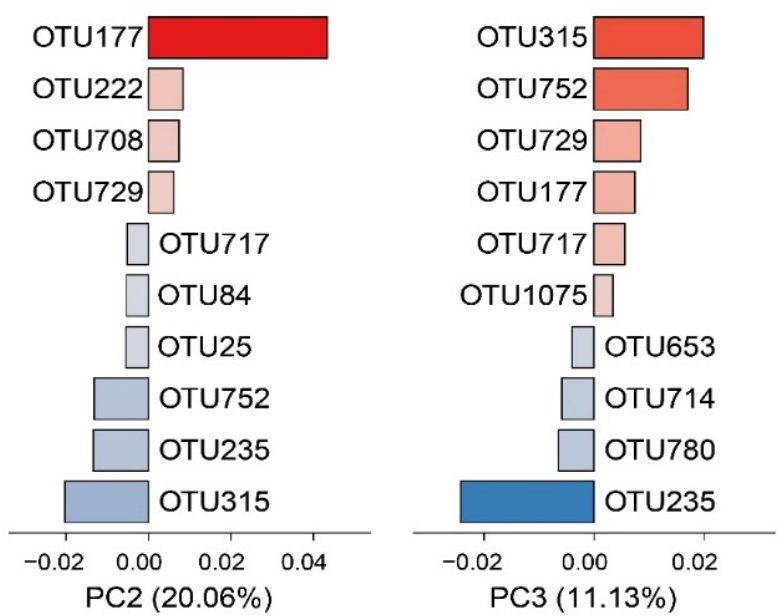

Figure 2. Alterations of the $\alpha$-diversity and $\beta$-diversity in microflora of mice after oral supplement with JP. (A) Microbial alpha diversity shown in different indices: Shannon, Ace, and Simpson indices. (B) $\beta$-diversity analysis of microflora using principal component analysis (PCA) based on OTUs. (C) The contribution of key OTUs with the greatest impact on PCA clustering. (D) Radar chart of the key OTUs in different groups. ${ }^{*} p<0.05,{ }^{* *} p<0.01$. 

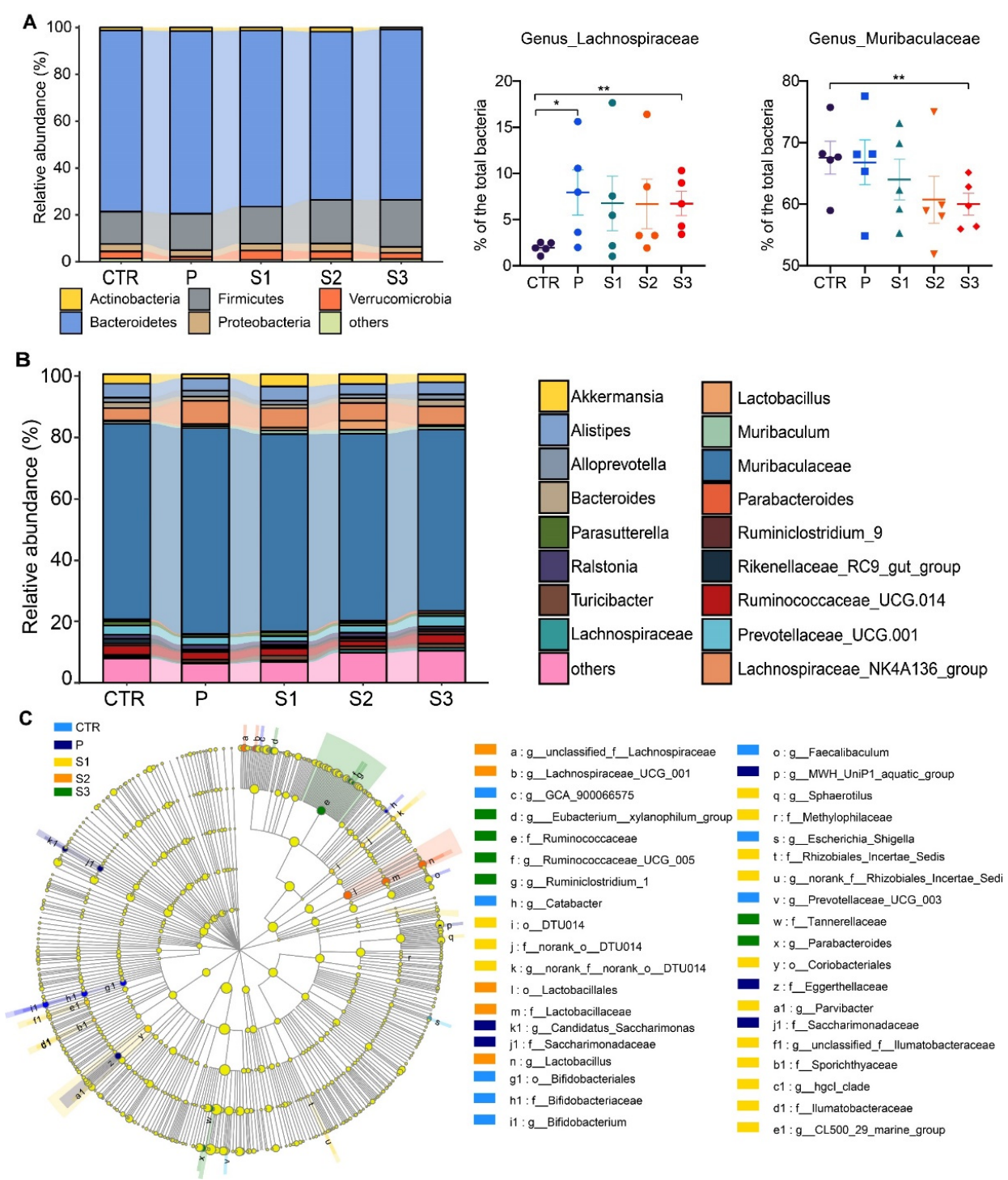

Figure 3. Taxonomic composition at phylum (A) and genus (B) levels and the difference in dominant microbiotas (C). $* p<0.05,{ }^{* *} p<0.01$.

\subsection{Effects of Jujube Powder (JP) Particle Size on SCFA Production and Gut Microbiota}

Jujube is rich in polysaccharides, dietary fiber, and other complex carbohydrates that can be fermented by microbes to produce SCFAs and provide energy and nutrients to intestinal epithelial cells. SCFAs have many health benefits including regulation of energy metabolism and immune system. Here, we first determined the production of SCFAs after oral supplementation with JP. Figure $4 \mathrm{~A}$ shows that the administration of JP to healthy mice greatly increased the production of acetate, propionate, butyrate, and valerianate. Next, weighted gene co-expression network analysis (WGCNA) was performed to recognize clusters of OTUs. These clusters are highly correlated with each other. A high-confidence scale-free network was constructed with soft threshold $\beta=5$ and scale-free $R^{2}=0.85$. Using the Dynamic Tree Cut algorithm, we obtained a total of seven OTU co-occurrence modules, as shown in Figure 4B. Figure 4C shows the relationship among OTUs in different modules and the classification of the five key OTUs we previously identified. Cluster analysis shows that the modules were divided into two categories, among which yellow, green, and turquoise modules belonged to one category, and the other three belonged to the other category (Figure 4D). Compared to other modules, the green, yellow, and brown modules were highly correlated with the production of SCFAs, as shown in Figure 4E. 
The green and yellow modules were positively correlated with the production of SCFAs, while the trend for the brown module was the opposite. Specifically, the abundance of OTUs in green modules was connected to the production of all SCFAs except propionate (Figure $4 \mathrm{~F}$ ). Figure $4 \mathrm{G}$ shows the module compositions in different groups, in which the abundance of green, yellow, and turquoise modules was significantly enhanced in the groups treated with JP and, more importantly, this tendency became more significant as the particle size of JP decreased. Figure $4 \mathrm{H}$ shows that these modules were enriched with Clostridiales, consistent with the results obtained from cases S2 and S3, where the abundance of Lachnospiraceae and Ruminococcaceae increased. The above results prove that the changes in gut microbiota were consistent with the production of short-chain fatty acids.
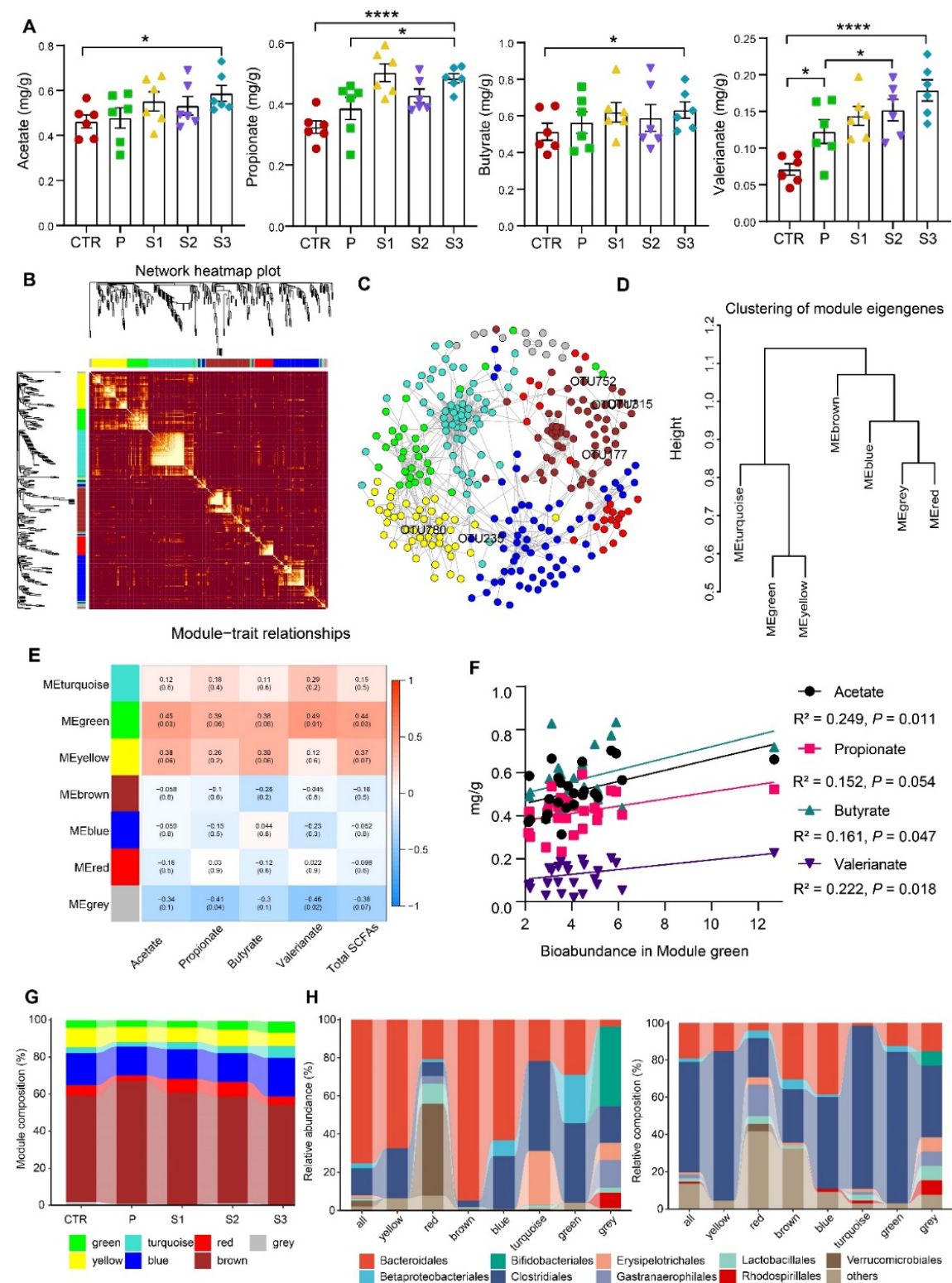

Figure 4. The relationship between the production of SCFAs and OTU clusters. (A) SCFA contents in cecum; (B) heatmap of topological overlap in the OTU network, where each row and column corresponds to an OTU. The dark red color represents low topological overlap, while the lighter orange color represents higher topological overlap; (C) network diagram with nodes colored according to each of the seven microbial clusters; (D) hierarchical clustering dendrogram of module eigen-OTUs; (E) correlation among modules and traits; (F) the regressed relationships between the keystone microbial cluster (green) and production of SCFAs; $(\mathbf{G})$ module changes among groups; (H) OTU abundance (left panel) and OTU composition (right panel) in each module $(n=6) .{ }^{*} p<0.05,{ }^{* * * *} p<0.0001$. 


\subsection{The Effects of JP Particle Size on the Enhancement of aPD-L1 Efficiency against Murine Colon Adenocarcinoma}

As shown in Figure 5A, in all JP and $\alpha$ PD-L1 combined treatment groups, the tumor growth rate slowed significantly compared to the $\alpha \mathrm{PD}-\mathrm{L} 1$ group (Figure $5 \mathrm{~B}$ ). Notably, the strongest inhibition of tumor growth took place in the S3 and $\alpha \mathrm{PD}-\mathrm{L} 1$ joint treatment group (tumor volume data and pictures of tumor-bearing mice are shown in Table S3 and Figure S1). The body weight of the mice increased steadily throughout the experimental period in all groups (Figure S2), indicating that the administration dosages of JP and $\alpha$ PD-L1 were safe. Next, we measured the SCFA level in the cecum on the 25th day. As shown in Figure 5C, the JP with smaller particles resulted in a higher SCFA productivity. To examine the microbe-induced immunologic changes, we measured the LPS (lipopolysaccharide) content in serum with ELISA. As shown in Figure 5D,E, smaller JP particles reduced the serum LPS and immunoglobulin A (IgA) levels. In the BugBase analysis, both Gram-negative bacteria (sources of LPS) (Figure 5G) and potentially pathogenic bacteria (Figure 5F) decreased more significantly in the case of ultrafine JP particles, as compared to the $\alpha$ PD-L1 group. These results indicate that JP may impact the mouse immune response through the metabolites of the gut microbiota such as SCFAs rather than the cellular components of bacteria. The implication of these results is that reducing the particle size of jujube powder is beneficial to enhance $\alpha$ PD-L1 efficiency against murine colon adenocarcinoma.

A

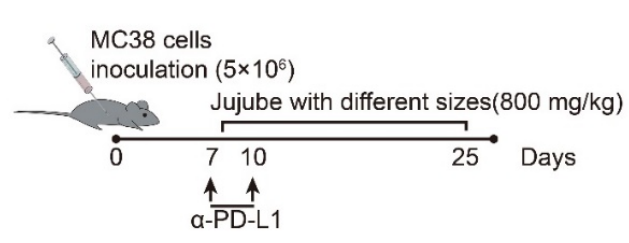

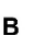

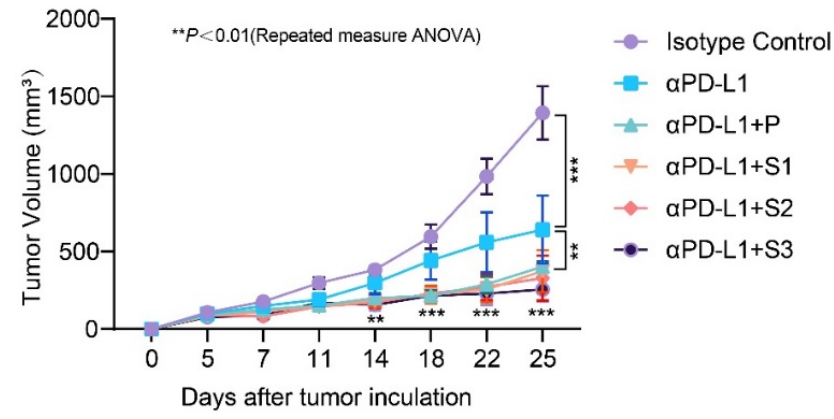

C
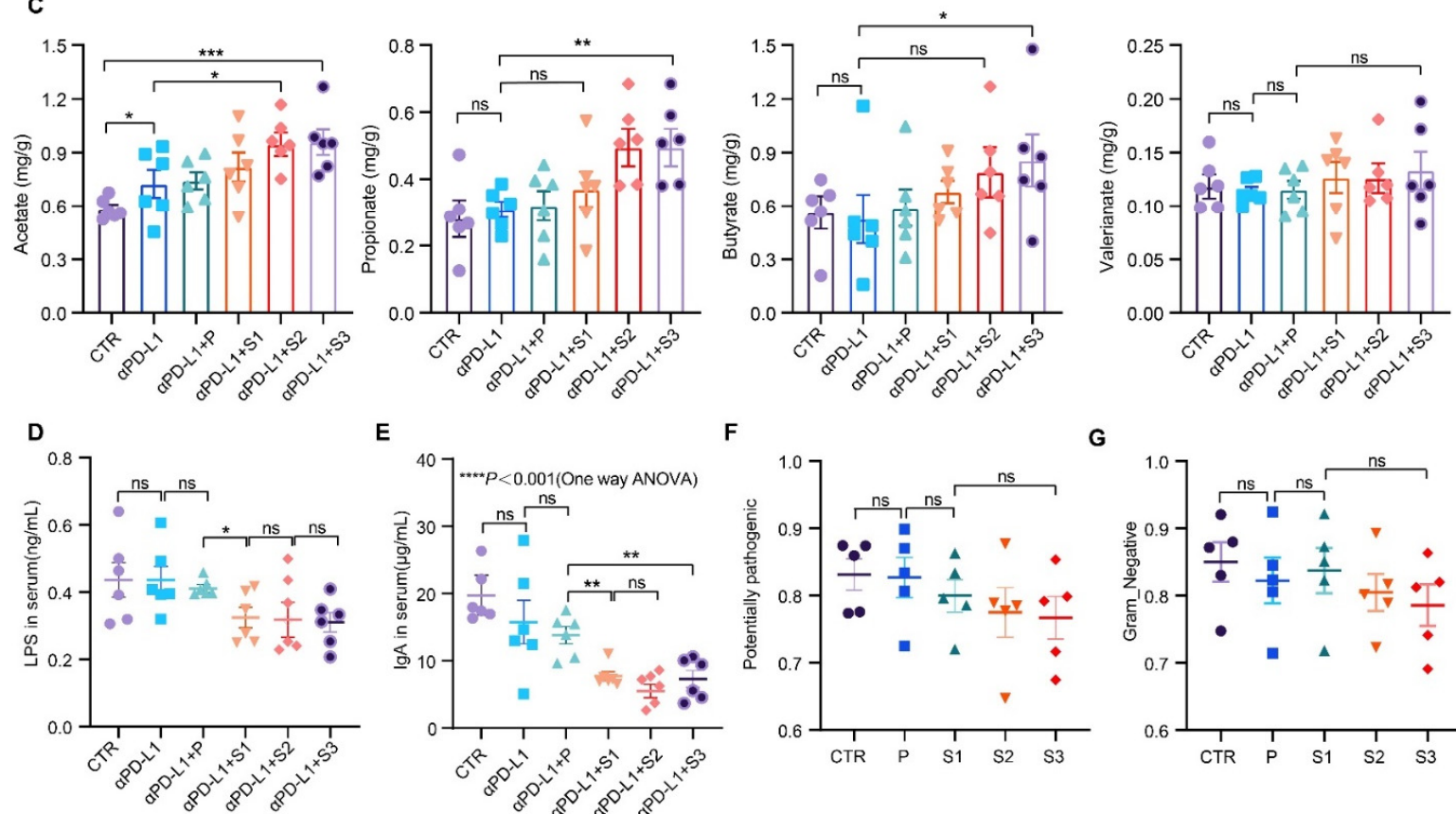

E

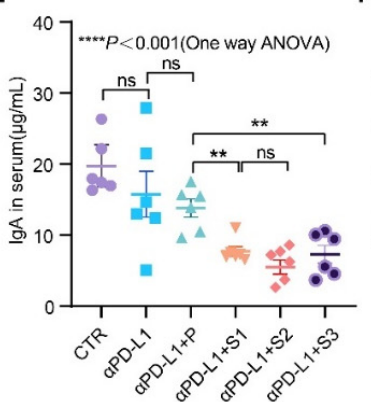

F

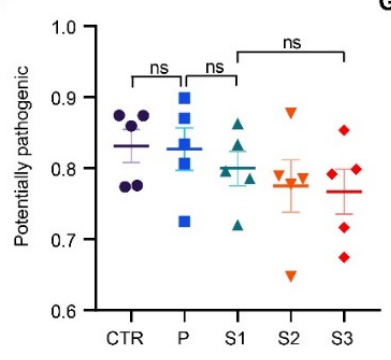

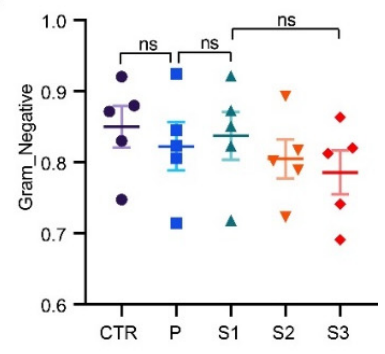

Figure 5. A reduction in JP particle size enhances its efficiency for anti-PD-L1 therapy. (A) Animal experiment design; (B) growth curve of tumor cells; (C) SCFA contents in cecum; (D) concentration of LPS in serum; (E) concentration of IgA in serum; (F) BugBase predicted potentially pathogenic and Gram-negative bacteria $(\mathbf{G})$ in the microbial communities $(n=6)$. Data indicate the mean $\pm \mathrm{SEM} ;{ }^{*} p<0.05,{ }^{* *} p<0.01,{ }^{* * *} p<0.001$. 


\subsection{Analysis of Tumor Immune Infiltration and System Immunity}

The effects of JP on the tumor-associated immune infiltrates were analyzed by FACS using the gating strategy defined in Figure 6A. Compared with the $\alpha$ PD-L1 group, there was no significant change in total leukocyte abundance in the gavage group (Figure 6B), but the differentiation of T-cell subtypes changed significantly (Figure $6 C-G$ ). A higher density of $\mathrm{CD}^{+} \mathrm{T}$ cells was observed in S2 and S3 groups (Figure 6D). It is noteworthy that $\alpha \mathrm{PD}-\mathrm{L} 1$ treatment resulted in a noticeable reduction in $\mathrm{CD} 4^{+} \mathrm{T}$ cells, whereas the administration of JP recovered and improved the ratio of $\mathrm{CD} 4^{+} \mathrm{T}$ cells; moreover, it led to a remarkable increase in Th17 cells, particularly in the $\mathrm{S} 3$ group. To understand how SCFAs increase $\mathrm{CD} 8^{+} \mathrm{T}$ cells in tumor-infiltrating lymphocytes, JP-treated and untreated mice mesenteric lymph nodes were isolated for RNA-sequencing (RNA-Seq). In the JP treatment group, many T-cell-associated genes were upregulated, especially the activated $\mathrm{CD}^{+} \mathrm{T}$ cells and $\mathrm{CD}^{+} \mathrm{T}$ cells, suggesting that JP could promote $\mathrm{CD} 8^{+} \mathrm{T}$-cell activation in mesenteric lymph nodes (Figure 6H). Gene set enrichment analysis (GSEA) shows that both gene sets directly associated with $\mathrm{T}$ cells were significantly upregulated, including T-cell differentiation and T-cell activation in mesenteric lymph nodes after JP treatment (Figure 6I). This also explains the origin of $\mathrm{CD}^{+} \mathrm{T}$ cells in tumors. These data suggest that, consistent with the growth rate of tumor volume, JP with smaller particle size can increase the population of $\mathrm{CD} 8^{+} \mathrm{T}$ cells in tumor-infiltrating lymphocytes.

A systematic antitumor immune response, in terms of the composition of immune cells in spleen, was determined by FACS. As shown in Figure 7A-D, the percentage of total leukocytes (CD45), NK cells (NK 1.1), and B cells (CD19) increased as the particle size of JP was reduced. Given the fact that NK cells destroy foreign cells (e.g., tumor cells) without prior sensitization, it is concluded that the systematic immunity was enhanced by the uptake of JP. Interestingly, the percentage of $\mathrm{CD} 8^{+} \mathrm{T}$ cells, $\mathrm{CD} 4^{+} \mathrm{T}$ cells, and Th17 cells did not show a significant change in spleen. In fact, the levels fell slightly with a decrease in particle size (Figure 7E-G), suggesting that the ultrafine JP particles were more advantageous in avoiding excess immune response.

\subsection{Effects of SCFAs on Immune Cell Composition In Vivo and In Vitro}

Since it has been reported that butyrate can induce cancer cell apoptosis [52], we first added butyrate to the drinking water of mice during $\alpha$ PD-L1 treatment (Figure $8 \mathrm{~A}$ ). Unexpectedly, oral supplement with butyrate did not enhance $\alpha$ PD-L1 efficiency, as shown in Figure 8B. Analysis of tumor-infiltrating lymphocytes also confirmed the previous results, as there was no significant difference in the ratio of total leukocytes and CD8 ${ }^{+}$ $\mathrm{T}$ cells between the $\alpha \mathrm{PD}-\mathrm{L} 1$ group and butyrate $+\alpha \mathrm{PD}-\mathrm{L} 1$ group (Figure $8 \mathrm{C}$ ). We also examined the effects of several other SCFAs on the immune system, including the immune cell composition in mesenteric lymph nodes (MLNs), spleen, and intestinal lamina propria (Figure 8D). However, oral supplementation with SCFAs did not increase their content in the cecum (Figure $8 \mathrm{E}$ ), which also explains why the $\mathrm{CD} 8^{+} \mathrm{T}$-cell and $\mathrm{CD} 4^{+} \mathrm{T}$-cell efficiency did not change in the MLNs, spleen, or intestinal lamina propria (Figure 8F). Lymphocytes were isolated from mouse MLNs and cultured with SCFAs in vitro (Figure 8G). Butyrate treatment resulted in an increased proportion of $\mathrm{CD} 8^{+} \mathrm{T}$ cells after incubation of $24 \mathrm{~h}$, while other SCFAs could also directly facilitate the $\mathrm{CD} 8^{+} \mathrm{T}$ cells after a longer incubation $(48 \mathrm{~h})$. The effects of SCFAs on $\mathrm{CD} 4^{+} \mathrm{T}$ cells may take a longer incubation time or require higher concentrations. These results indicate that direct supplementation of short-chain fatty acids could not increase their levels in the colon. Therefore, it could not stimulate the differentiation of immune cells in the mesenteric lymph nodes. 


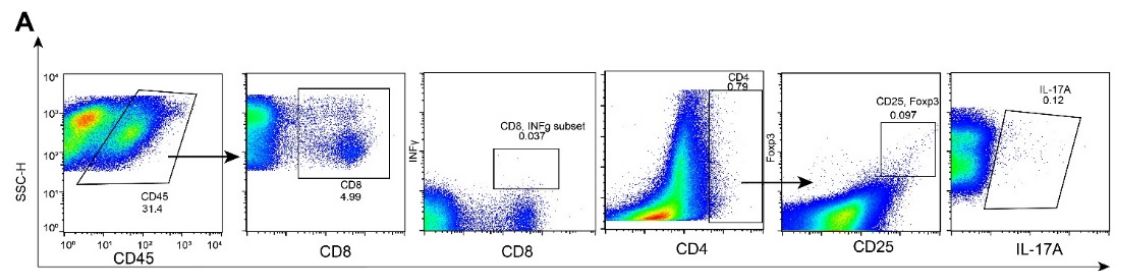

B

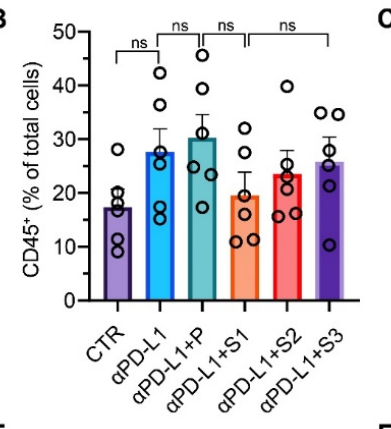

E

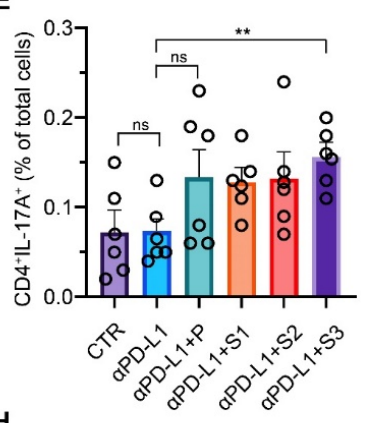

H

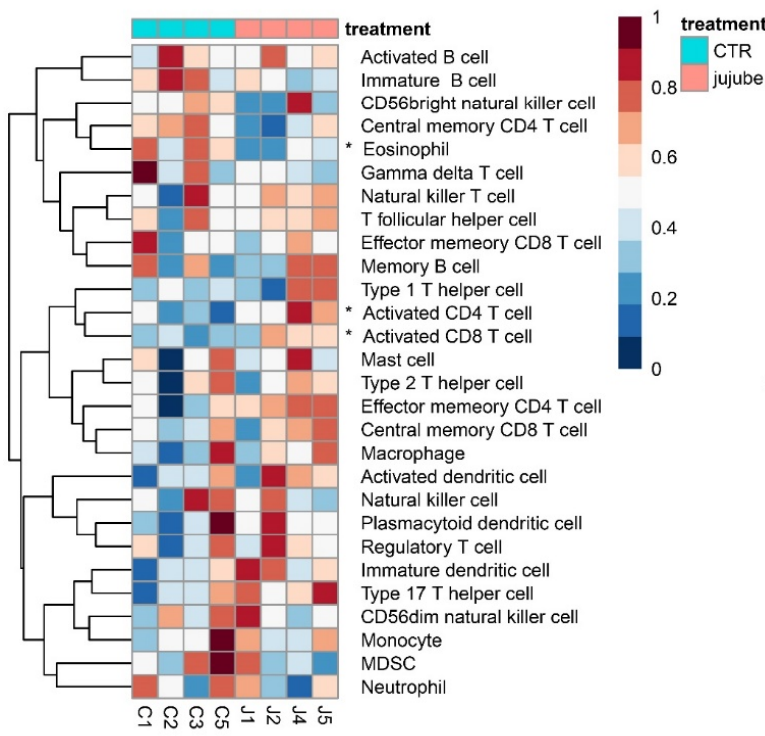

C

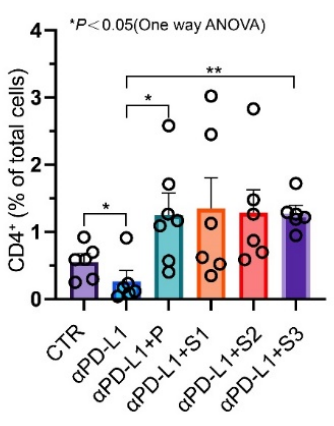

F

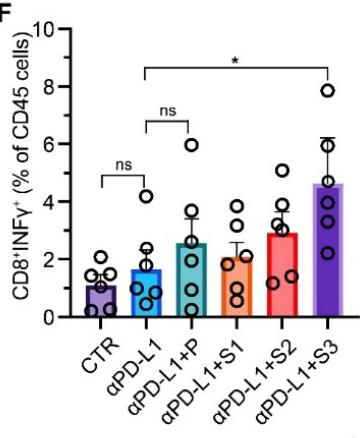

D ${ }^{*} P<0.05$ (One way ANOVA)
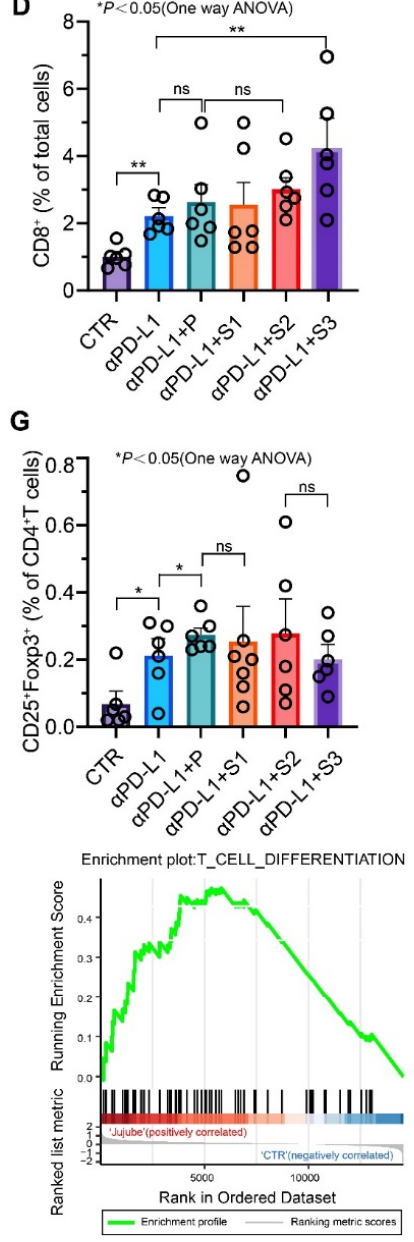

Enrichment plot:
POSITIVE_REGULATION_OF_ACTIVATED_T_CELL_PROLIFERATION

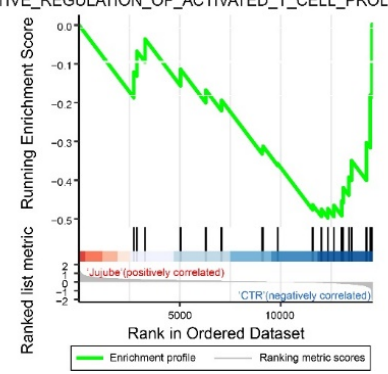

Figure 6. JP enhances the infiltration of immune cells in the TME. (A) Representative flow cytometry plots showing the expression of $\mathrm{CD} 45, \mathrm{CD}^{+}$, Th17, $\mathrm{CD} 4^{+}$, regulatory $\mathrm{T}$ cells (Tregs) and cytotoxic $\mathrm{CD} 8^{+} \mathrm{T}$ cells in tumor tissues; (B-G) percentage of $\mathrm{CD}^{2} 5^{+}$cells, $\mathrm{CD} 4^{+} \mathrm{T}$ cells, $\mathrm{CD} 8^{+} \mathrm{T}$ cells, Th17 cells, and cytotoxic $\mathrm{CD} 8^{+} \mathrm{T}$ cells among $\mathrm{CD} 8^{+} \mathrm{T}$ cells and Tregs among $\mathrm{CD} 4^{+} \mathrm{T}$ cells in the tumor tissues; (H) RNA-seq analysis of mesenteric lymph nodes from wild-type and JP-treated mice ( $n=4$ per group); (I) GSEA analysis of T-cell differentiation and activation. The diagram plots the GSEA for two gene sets upregulated in JP-treated groups (left side, Jujube; right side, CTR). The vertical axis in the upper graph denotes the enrichment score (ES), while the barcode plot denotes the position of genes. NES, normalized ES; FDR, false discovery rate. Data indicate the mean $\pm \mathrm{SEM} ;{ }^{*} p<0.05,{ }^{* *} p<0.01$. 

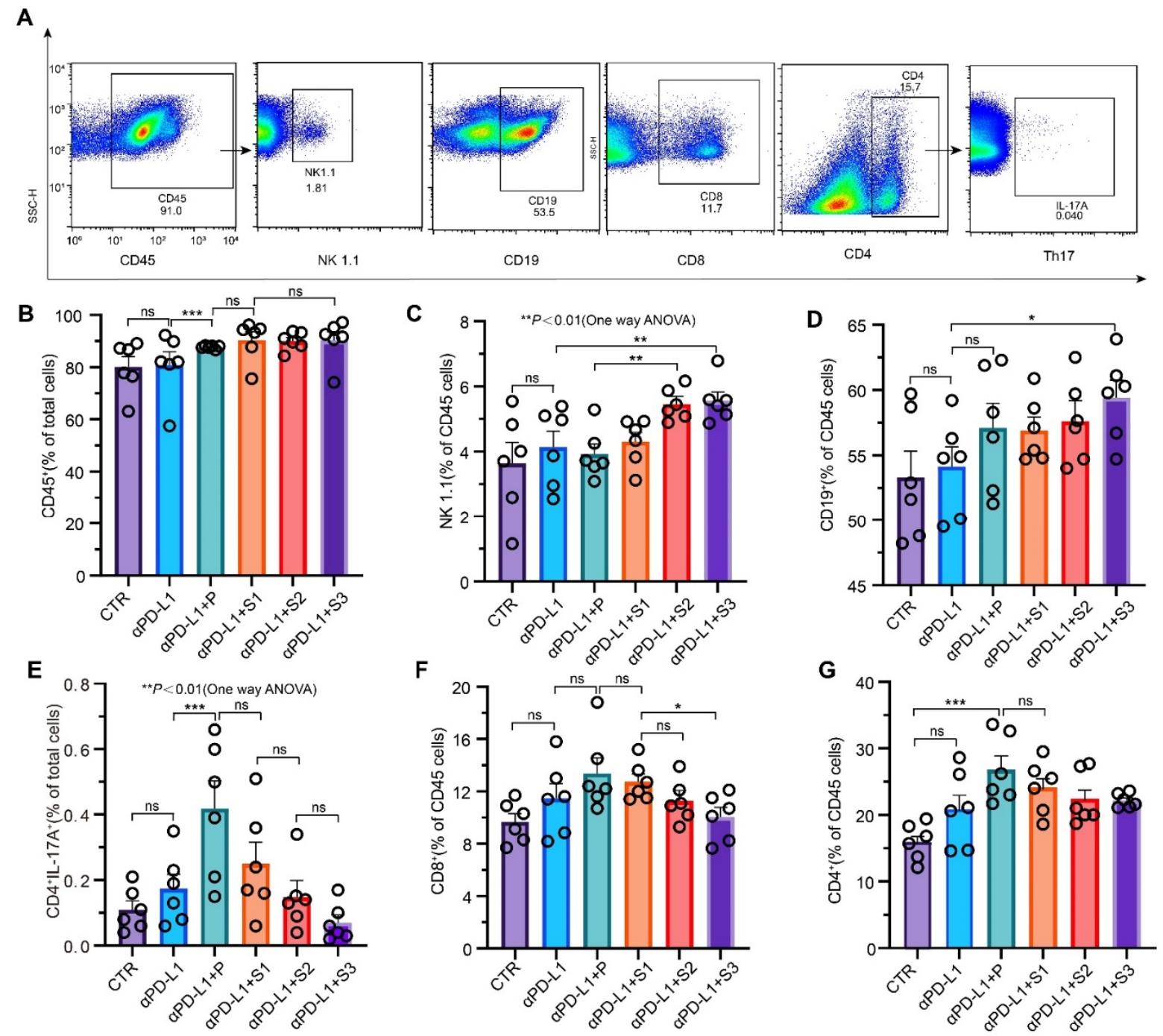

Figure 7. After administration with JP, the gut microbiota shows enhanced systemic immunity. (A) Representative flow cytometry plots showing the expressions of CD45, NK 1.1, CD19, Th17, CD4 ${ }^{+}$, and CD8 ${ }^{+} \mathrm{T}$ cells in spleen tissues; (B-G) percentages of CD45 cells, NK 1.1 cells, CD19 cells, Th17 cells, CD8 ${ }^{+} \mathrm{T}$ cells, and CD4 ${ }^{+}$Tcells in spleen tissues. Data indicate the mean $\pm \mathrm{SEM}$; $p<0.05,{ }^{* *} p<0.01,{ }^{* * *} p<0.001$. 

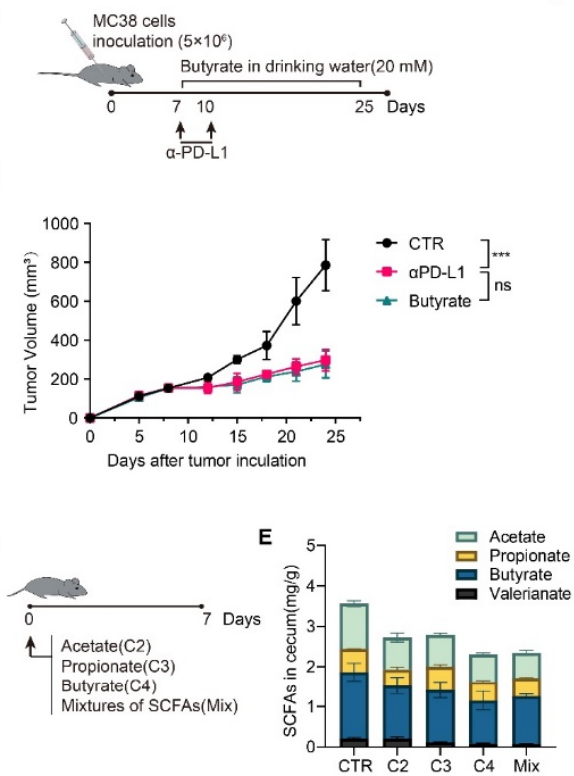

Spleen
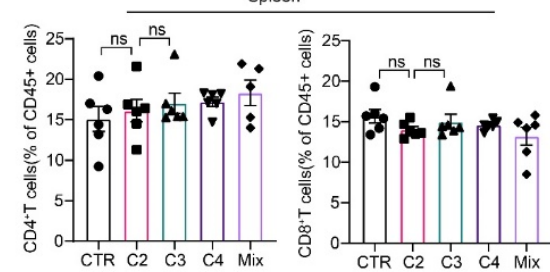

c

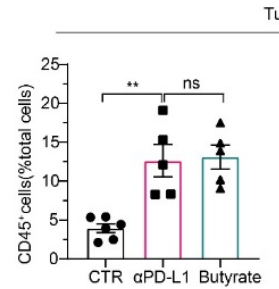

mor
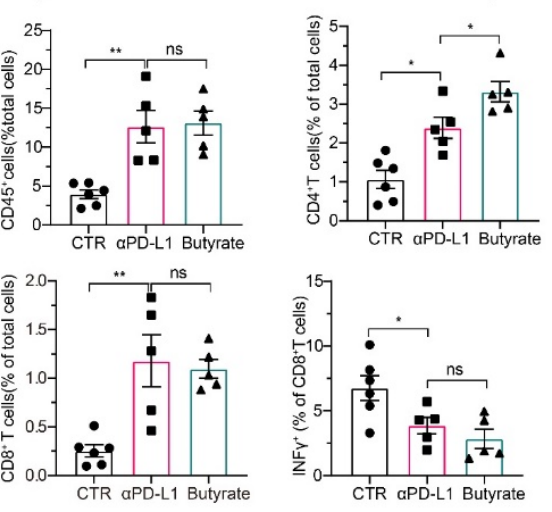

$\mathbf{F}$
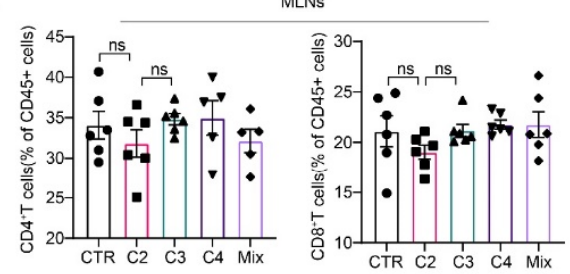

Intestinal lamina propria
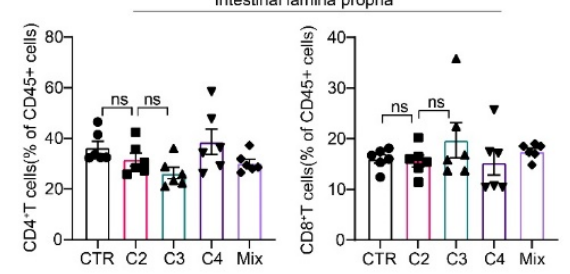

G
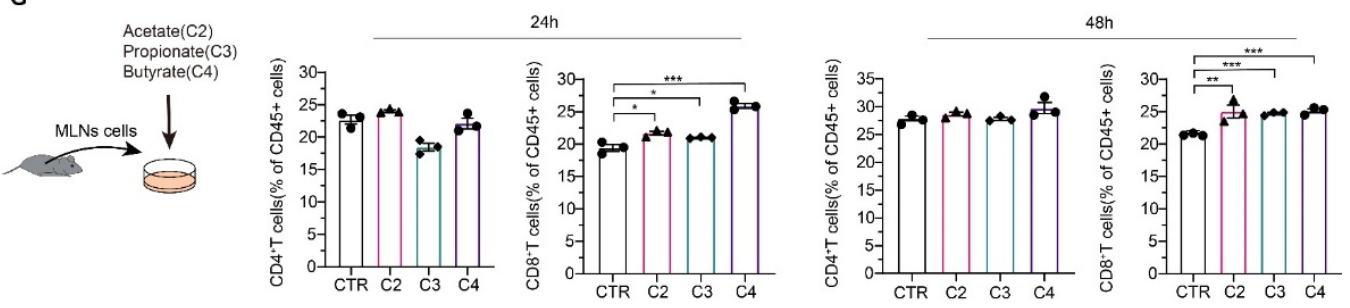

Figure 8. Effects of SCFAs on immune cell composition in vivo and in vitro. (A) Animal experiment design $(n=6)$; (B) growth curve of tumor cells; (C) analysis of tumor-infiltrating lymphocytes by FACS; (D) animal experiment design: C57BL/ 6 mice were treated with $80 \mathrm{mM}$ acetate (C2), propionate (C3), butyrate (C4), and mixtures of SCFAs (40 mM C2, 40 mM C3, and 40 mM C4) in drinking water for 1 week; (E) SCFA contents in cecum; (F) CD4 ${ }^{+} \mathrm{T}_{\text {cells and CD8 }}{ }^{+} \mathrm{T}$ cells in MLNs, spleen, and intestinal lamina propria were examined. (G) SCFAs directly affect CD4 ${ }^{+} \mathrm{T}$ cells and CD8 ${ }^{+} \mathrm{T}$ cells in MLNs in vitro. Data indicate the mean $\pm \mathrm{SEM} ;{ }^{*} p<0.05,{ }^{* *} p<0.01,{ }^{* * *} p<0.001$.

\section{Discussion}

Mei Kong and coworkers have shown that glutamine supplementation can block melanoma tumor growth through suppressing epigenetically activated oncogenic pathways, which can serve as a potential dietary intervention [53]. Xiaohuan Guo and coworkers reported that butyrate can directly enhance the $\mathrm{CD} 8^{+} \mathrm{T}$ cell immune response and enhance chemotherapy efficacy [54]. Whether dietary interventions are useful in colorectal cancer remains to be explored. In this study, we discovered that oral administration of jujube powder (JP) is able to ameliorate the mouse gut biota with an enriched population of Lachnospiraceae and Ruminococcaceae, an enhanced production of SCFAs, and an improved tumor immune infiltration and systemic immunity, which collectively contribute to the higher antitumor efficiency of $\alpha$ PD-L1 in vivo. The therapeutic effects were most significant in the case of using ultrafine JP particles. 
Here, we found that the smallest JP particles showed a smoothened spherical-like shape (Figure 1A), which is helpful for its role as a prebiotic [36,55,56]. FTIR results showed that ultrafine grinding did not change the group structure of jujube powders or the main components. However, compared with the ordinary powder, the absorption peak strength of ultrafine jujube powder was intensified, which indicates that the number of functional groups increased. This phenomenon could be due to an increased specific surface area [57]. It is also noteworthy that the magnitude of zeta potential was reduced as the particle size decreased, indicating an enhanced uptake of JP particles by the gut microbiota. These microbes adhere to the particle surface and release hydrolytic enzymes to hydrolyze macromolecular nutrients before absorption. Therefore, changes in the surface chemistry of substrates may affect the adhesion behavior of microbes. Min and Akbulut demonstrated that the surface chemistry of substrate could influence the kinetics and thermodynamics of bacterial adhesion $[58,59]$. Cooper et al. showed that the bacterial adhesion was higher on hydrophobic surfaces $[60,61]$. The adhesive forces between substrate and bacterium arise through van der Waals and electrostatic double-layer interactions [62]. On the basis of the above discussion, we conjecture that ultrafine jujube powder is beneficial for microbial adhesion and nutrient utilization.

In particular, we observed that the abundance of Lachnospiraceae and Ruminococcaceae increased in groups treated with ultrafine powders. In order to exclude the influence of microbes carried by jujube powder itself on the results, we detected the microbial purity of JP (Table S4). The total amount of microbes in JP was below $10 \mathrm{CFU} / \mathrm{g}$, which is much less than that reported in the gut, being $4 \times 10^{13}[63,64]$. Moreover, the Clostridium genus were not found in JP. We, thus, concluded that the changes in gut microbiota were contributed by the JP rather than the microbes on the surface of JP. These two species are thought to be butyrogenic populations belonging to clostridial cluster XIV (Lachnospiraceae) and cluster IV (Ruminococcaceae) [65], which lead to an improvement of nondigestible carbohydrate fermentation profiles and an increase in SCFA production. This flora composition may, thus, contribute to increased energy harvest from the diet [66]. Hence, we examined the content of SCFAs in the cecum. Consistently, the reduction in particle size accelerated SCFA production, which was consistent with the changes in bacterial flora composition. WGCNA further pointed out a relationship between Clostridiales and SCFA production, supporting the previous assertion. Higher stool SCFA concentrations in adults have been linked to greater intake of dietary fiber, particularly from foods rich in fermentable fibers [67]. A large number of studies have shown that the physical form and structure of dietary fiber (DF) greatly influence its microbiota-modulating activity [56,68]. Moreover, our study showed that particle size had an impact on the availability of DF in jujube powder (Table S2), which in turn may influence the fermentability of DF [69], boosting SCFA production [70].

The differential structure of the gut microbiota may influence therapeutic responses to ICI through impacting the tumor microenvironment, including infiltrating immune cells that can stimulate (such as $\mathrm{CD} 8^{+} \mathrm{T}$ cells) an immune response. We observed that the responders to anti-PD-1 therapy are rich in Clostridiales, Ruminococcaceae, and Lachnospiraceae $[4,6,35]$, which are positively correlated with $C D 8^{+} \mathrm{T}$-cell infiltration in the tumor [6]. Recently, Tomita et al. showed that Clostridium butyricum, specialized in producing butyrate, may have a positive impact on the therapeutic efficacy of ICI in patients with lung cancer [71]. Here, we observed an increase in these species in the S3 group. Higher levels of SCFAs produced by these microbes further stimulate immune cell differentiation in the gut. After being primed by dendritic cells (DCs) in draining mesenteric lymph nodes (MLNs) of the gut, B and T cells, including Tregs and Th17 cells, could circulate systemically to facilitate immune responses at distant sites [72]. A significant positive correlation has been confirmed between the $\mathrm{CD} 8^{+} \mathrm{T}$ cell infiltrate in the tumor and abundance of the Clostridiales and Ruminococcaceae [6]. Given that Th1 cells $\left(\mathrm{CD} 4^{+} \mathrm{IFN} \gamma^{+}\right)$play a key role in activating $\mathrm{CD} 8^{+} \mathrm{T}$ cells, we also analyzed the tumor-infiltrating $\mathrm{CD} 4^{+} \mathrm{T}$ cells. FACS results revealed a significant increase in the infiltration of $\mathrm{CD}^{+} \mathrm{T}$ cells in mice treated with JP. Administration of the combination treatment with anti-PD-L1 antibody and JP 
increased the population and antitumor function of DCs, thereby promoting recruitment of activated $\mathrm{CD} 8^{+} \mathrm{T}$ cells to the tumor microenvironment. In addition, we also found that direct supplementation of SCFAs did not improve tumor-infiltrating lymphocytes, which may be due to digestion and absorption after oral administration, preventing an effect in the intestine. SCFAs have also been shown to influence immunity via IgA production by plasma cells, which may affect local immunity [73]. The reduction in plasma IgA secretion after JP administration suggests a more complete intestinal mucosal barrier.

Although our current research achieved encouraging results in syngeneic tumor models, complex genetically engineered mouse models will be valuable for predictive evaluation of tumor immunotherapies in the preclinical setting, which can accurately reflect the autochthonous tumor microenvironment. Different mouse models, as discussed by Olson [74], will be investigated in our future work.

\section{Conclusions}

Given all the findings of this work, we conclude that the administration of ultrafine jujube powder (JP) alters intestinal flora composition as evidenced by the high abundance of Clostridiales, including Ruminococcaceae and Lachnospiraceae, as well as enhanced SCFA production. Ultrafine JP particles greatly improved the response of anti-PD-L1 treatment, as shown by an intensified infiltration of $\mathrm{CD}^{+} \mathrm{T}$ cells into the TME and maintenance of the intestinal mucosal barrier. Our study indicates that, combined with nutritional interventions during the treatment of immune checkpoint inhibitors, the effectiveness of tumor immunotherapy can be improved. Future efforts will be directed at understanding the molecular details of the interaction among nutrients, gut microbiota, and immune response. Nutritional intervention in cancer prevention is also worthy of attention.

Supplementary Materials: The following are available online at https:/ /www.mdpi.com/article/10 .3390/cancers13163987/s1, Table S1: Physicochemical properties of P, S1, S2 and S3, Table S2: Effects of ultrafine grinding on the contents of dietary fiber in JP, Table S3: Tumor volume (mm3), Table S4: jujube powder's microbial purity, Figure S1: Picture of tumor-bearing mice among different groups, Figure S2: Body weight were measured twice weekly $(n=6)$, Figure S3: LDA Score of LEfSe analysis.

Author Contributions: Conceptualization, N.J., L.W., G.J., and Z.L.; data curation, N.J. and L.W.; formal analysis, L.W.; investigation, N.J. and H.Z.; methodology, L.W. and G.J.; project administration, N.J. and H.Z.; supervision, Z.L.; validation, G.J. and Z.L.; writing-original draft, N.J.; writingreview and editing, N.J., L.W., G.J., and Z.L. All authors have read and agreed to the published version of the manuscript.

Funding: This work was funded by Xinjiang Tianchen-Zhihui Information Technology Co., Ltd. (Xinjiang, China) (No. 20192000168) and Xinjiang Tianjianhemu Biotech Co., Ltd. (Xinjiang, China) (No. 20172000941).

Institutional Review Board Statement: This study was conducted according to the guidelines of the Institutional Animal Care and Use Committees of Tsinghua University for animal welfare (approval ID SYXK2019-0037).

Informed Consent Statement: Not applicable.

Data Availability Statement: The 16S rDNA sequencing dataset was deposited in the SRA database of NCBI with accession ID SUB9454167. Other data that support the findings of this study are available upon reasonable request from the corresponding author.

Acknowledgments: We thank Jianzhong Wu (Environmental and Chemical Engineering, University of California, Riverside, CA, USA) for expert guidance.

Conflicts of Interest: The authors declare no conflict of interest. The funders had no role in the design of the study; in the collection, analyses, or interpretation of data; in the writing of the manuscript, or in the deci-sion to publish the results. 


\section{References}

1. Zhang, T.; Xie, J.; Arai, S.; Wang, L.; Shi, X.; Shi, N.; Ma, F.; Chen, S.; Huang, L.; Yang, L.; et al. The efficacy and safety of anti-PD-1/PD-L1 antibodies for treatment of advanced or refractory cancers: A meta-analysis. Oncotarget 2016, 7, 73068-73079. [CrossRef] [PubMed]

2. $\quad$ D'Angelo, S.P.; Larkin, J.; Sosman, J.A.; Lebbe, C.; Brady, B.; Neyns, B.; Schmidt, H.; Hassel, J.C.; Hodi, F.S.; Lorigan, P.; et al. Efficacy and Safety of Nivolumab Alone or in Combination With Ipilimumab in Patients With Mucosal Melanoma: A Pooled Analysis. J. Clin. Oncol. 2017, 35, 226-235. [CrossRef]

3. Topalian, S.L.; Drake, C.G.; Pardoll, D.M. Immune Checkpoint Blockade: A Common Denominator Approach to Cancer Therapy. Cancer Cell 2015, 27, 450-461. [CrossRef]

4. Matson, V.; Fessler, J.; Bao, R.; Chongsuwat, T.; Zha, Y.; Alegre, M.-L.; Luke, J.J.; Gajewski, T.F. The commensal microbiome is associated with anti-PD-1 efficacy in metastatic melanoma patients. Science 2018, 359, 104-108. [CrossRef]

5. Routy, B.; Le Chatelier, E.; Derosa, L.; Duong, C.P.M.; Alou, M.T.; Daillere, R.; Fluckiger, A.; Messaoudene, M.; Rauber, C.; Roberti, M.P.; et al. Gut microbiome influences efficacy of PD-1-based immunotherapy against epithelial tumors. Science 2018, $359,91-97$. [CrossRef]

6. Gopalakrishnan, V.; Spencer, C.N.; Nezi, L.; Reuben, A.; Andrews, M.C.; Karpinets, T.V.; Prieto, P.A.; Vicente, D.; Hoffman, K.; Wei, S.C.; et al. Gut microbiome modulates response to anti-PD-1 immunotherapy in melanoma patients. Science 2018, 359, 97-103. [CrossRef]

7. Frankel, A.E.; Coughlin, L.A.; Kim, J.; Froehlich, T.W.; Xie, Y.; Frenkel, E.P.; Koh, A.Y. Metagenomic Shotgun Sequencing and Unbiased Metabolomic Profiling Identify Specific Human Gut Microbiota and Metabolites Associated with Immune Checkpoint Therapy Efficacy in Melanoma Patients. Neoplasia 2017, 19, 848-855. [CrossRef]

8. Chaput, N.; Lepage, P.; Coutzac, C.; Soularue, E.; Le Roux, K.; Monot, C.; Boselli, L.; Routier, E.; Cassard, L.; Collins, M.; et al. Baseline gut microbiota predicts clinical response and colitis in metastatic melanoma patients treated with ipilimumab. Ann. Oncol. 2017, 28, 1368-1379. [CrossRef] [PubMed]

9. Owens, B. Gut bacteria link to immunotherapy sparks interest. Nat. Biotechnol. 2018, 36, 121-123. [CrossRef] [PubMed]

10. Wu, G.D.; Chen, J.; Hoffmann, C.; Bittinger, K.; Chen, Y.-Y.; Keilbaugh, S.A.; Bewtra, M.; Knights, D.; Walters, W.A.; Knight, R.; et al. Linking Long-Term Dietary Patterns with Gut Microbial Enterotypes. Science 2011, 334, 105-108. [CrossRef]

11. Sivan, A.; Corrales, L.; Hubert, N.; Williams, J.B.; Aquino-Michaels, K.; Earley, Z.M.; Benyamin, F.W.; Lei, Y.M.; Jabri, B.; Alegre, M.-L.; et al. Commensal Bifidobacterium promotes antitumor immunity and facilitates anti-PD-L1 efficacy. Science 2015, 350, 1084-1089. [CrossRef]

12. Davar, D.; Dzutsev, A.K.; McCulloch, J.A.; Rodrigues, R.R.; Chauvin, J.-M.; Morrison, R.M.; Deblasio, R.N.; Menna, C.; Ding, Q.; Pagliano, O.; et al. Fecal microbiota transplant overcomes resistance to anti-PD-1 therapy in melanoma patients. Science 2021, 371, 595-602. [CrossRef]

13. David, L.A.; Maurice, C.F.; Carmody, R.N.; Gootenberg, D.B.; Button, J.E.; Wolfe, B.E.; Ling, A.V.; Devlin, A.S.; Varma, Y.; Fischbach, M.A.; et al. Diet rapidly and reproducibly alters the human gut microbiome. Nature 2014, 505, 559-563. [CrossRef]

14. Faith, J.J.; McNulty, N.P.; Rey, F.E.; Gordon, J.I. Predicting a Human Gut Microbiota's Response to Diet in Gnotobiotic Mice. Science 2011, 333, 101-104. [CrossRef]

15. Ley, R.E.; Hamady, M.; Lozupone, C.; Turnbaugh, P.J.; Ramey, R.R.; Bircher, J.S.; Schlegel, M.L.; Tucker, T.A.; Schrenzel, M.D.; Knight, R.; et al. Evolution of mammals and their gut microbes. Science 2008, 320, 1647-1651. [CrossRef]

16. Zhang, S.-L.; Mao, Y.-Q.; Zhang, Z.-Y.; Li, Z.-M.; Kong, C.-Y.; Chen, H.-L.; Cai, P.-R.; Han, B.; Ye, T.; Wang, L.-S. Pectin supplement significantly enhanced the anti-PD-1 efficacy in tumor-bearing mice humanized with gut microbiota from patients with colorectal cancer. Theranostics 2021, 11, 4155-4170. [CrossRef]

17. Gao, Q.-H.; Wu, C.-S.; Wang, M. The Jujube (Ziziphus Jujuba Mill.) Fruit: A Review of Current Knowledge of Fruit Composition and Health Benefits. J. Agric. Food Chem. 2013, 61, 3351-3363. [CrossRef]

18. Xu, J.P.; Xu, J.P. Natural Substances for Cancer Prevention; CRC Press: Boca Raton, FL, USA, 2018.

19. Choi, S.-H.; Ahn, J.-B.; Kozukue, N.; Levin, C.E.; Friedman, M. Distribution of Free Amino Acids, Flavonoids, Total Phenolics, and Antioxidative Activities of Jujube (Ziziphus jujuba) Fruits and Seeds Harvested from Plants Grown in Korea. J. Agric. Food Chem. 2011, 59, 6594-6604. [CrossRef] [PubMed]

20. Daneshmand, F.; Zare-Zardini, H.; Ebrahimi, L. Investigation of the antimicrobial activities of Snakin-Z, a new cationic peptide derived from Zizyphus jujuba fruits. Nat. Prod. Res. 2013, 27, 2292-2296. [CrossRef] [PubMed]

21. Zhou, Y.; Li, Y.; Zhou, T.; Zheng, J.; Li, S.; Li, H.-B. Dietary Natural Products for Prevention and Treatment of Liver Cancer. Nutrients 2016, 8, 156. [CrossRef] [PubMed]

22. Li, J.; Shan, L.; Liu, Y.; Fan, L.; Ai, L. Screening of a functional polysaccharide from Zizyphus Jujuba cv. Jinsixiaozao and its property. Int. J. Biol. Macromol. 2011, 49, 255-259. [CrossRef]

23. Zou, M.; Chen, Y.; Sun-Waterhouse, D.; Zhang, Y.; Li, F. Immunomodulatory acidic polysaccharides from Zizyphus jujuba cv. Huizao: Insights into their chemical characteristics and modes of action. Food Chem. 2018, 258, 35-42. [CrossRef] [PubMed]

24. Cai, Y.; Zhou, X.; Han, A.; Chen, P.; Bai, H. In vitro immunological and anti-complementary activities of two water-soluble lignins from Zizyphus jujube cv. Jinchangzao. Int. J. Biol. Macromol. 2017, 105, 204-212. [CrossRef] 
25. Chen, J.; Li, Z.; Maiwulanjiang, M.; Zhang, W.L.; Zhan, J.Y.X.; Lam, C.T.W.; Zhu, K.Y.; Yao, P.; Choi, R.C.Y.; Lau, D.T.W.; et al. Chemical and Biological Assessment of Ziziphus jujuba Fruits from China: Different Geographical Sources and Developmental Stages. J. Agric. Food Chem. 2013, 61, 7315-7324. [CrossRef]

26. Wang, L.; Jing, N.; Liu, X.; Jiang, G.; Liu, Z. Nurturing and modulating gut microbiota with jujube powder to enhance anti-PD-L1 efficiency against murine colon cancer. J. Funct. Foods 2020, 64. [CrossRef]

27. Peng, M.; Biswas, D. Short chain and polyunsaturated fatty acids in host gut health and foodborne bacterial pathogen inhibition. Crit. Rev. Food Sci. 2017, 57, 3987-4002. [CrossRef] [PubMed]

28. Tao, J.; Li, S.; Gan, R.-Y.; Zhao, C.-N.; Meng, X.; Li, H.-B. Targeting gut microbiota with dietary components on cancer: Effects and potential mechanisms of action. Crit. Rev. Food Sci. 2020, 60, 1025-1037. [CrossRef]

29. Trompette, A.; Gollwitzer, E.S.; Pattaroni, C.; Lopez-Mejia, I.C.; Riva, E.; Pernot, J.; Ubags, N.; Fajas, L.; Nicod, L.P.; Marsland, B.J. Dietary Fiber Confers Protection against Flu by Shaping Ly6c(-) Patrolling Monocyte Hematopoiesis and CD8(+) T Cell Metabolism. Immunity 2018, 48, 992-1005. [CrossRef]

30. Huang, C.-H.; Shen, C.-C.; Liang, Y.-C.; Jan, T.-R. The probiotic activity of Lactobacillus murinus against food allergy. J. Funct. Foods 2016, 25, 231-241. [CrossRef]

31. Tanoue, T.; Morita, S.; Plichta, D.R.; Skelly, A.N.; Suda, W.; Sugiura, Y.; Narushima, S.; Vlamakis, H.; Motoo, I.; Sugita, K.; et al. A defined commensal consortium elicits CD8 T cells and anti-cancer immunity. Nature 2019, 565, 600-605. [CrossRef] [PubMed]

32. Mager, L.F.; Burkhard, R.; Pett, N.; Cooke, N.C.A.; Brown, K.; Ramay, H.; Paik, S.; Stagg, J.; Groves, R.A.; Gallo, M.; et al. Microbiome-derived inosine modulates response to checkpoint inhibitor immunotherapy. Science 2020, 369, 1481-1489. [CrossRef]

33. Nomura, M.; Nagatomo, R.; Doi, K.; Shimizu, J.; Baba, K.; Saito, T.; Matsumoto, S.; Inoue, K.; Muto, M. Association of Short-Chain Fatty Acids in the Gut Microbiome With Clinical Response to Treatment With Nivolumab or Pembrolizumab in Patients With Solid Cancer Tumors. JAMA Netw. Open 2020, 3, e202895. [CrossRef] [PubMed]

34. Gill, P.A.; van Zelm, M.C.; Muir, J.G.; Gibson, P.R. short chain fatty acids as potential therapeutic agents in human gastrointestinal and inflammatory disorders. Aliment. Pharm. Therap 2018, 48, 15-34. [CrossRef]

35. Smith, P.M.; Howitt, M.R.; Panikov, N.; Michaud, M.; Gallini, C.A.; Bohlooly-Y, M.; Glickman, J.N.; Garrett, W.S. The Microbial Metabolites, Short-Chain Fatty Acids, Regulate Colonic T-reg Cell Homeostasis. Science 2013, 341, 569-573. [CrossRef]

36. Dubey, R.; Toh, Y.-R.; Yeh, A.-I. Enhancing cellulose functionalities by size reduction using media-mill. Sci. Rep. 2018, 8, 11343. [CrossRef]

37. Lu, H.; Gui, Y.; Zheng, L.; Liu, X. Morphological, crystalline, thermal and physicochemical properties of cellulose nanocrystals obtained from sweet potato residue. Food Res. Int. 2013, 50, 121-128. [CrossRef]

38. Huang, X.; Liang, K.-h.; Liu, Q.; Qiu, J.; Wang, J.; Zhu, H. Superfine grinding affects physicochemical, thermal and structural properties of Moringa Oleifera leaf powders. Ind. Crop. Prod. 2020, 151, 112472. [CrossRef]

39. Wang, D.; Zhao, Y.; Jiao, Y.; Yu, L.; Yang, S.; Yang, X. Antioxidative and hepatoprotective effects of the polysaccharides from Zizyphus jujube cv. Shaanbeitanzao. Carbohyd. Polym. 2012, 88, 1453-1459. [CrossRef]

40. Chen, C.; Huang, Q.; Li, C.; Fu, X. Hypoglycemic effects of a Fructus Mori polysaccharide in vitro and in vivo. Food Funct. 2017, 8, 2523-2535. [CrossRef] [PubMed]

41. Cavaglieri, C.R.; Nishiyama, A.; Fernandes, L.C.; Curi, R.; Miles, E.A.; Calder, P.C. Differential effects of short-chain fatty acids on proliferation and production of pro- and anti-inflammatory cytokines by cultured lymphocytes. Life. Sci. 2003, 73, 1683-1690. [CrossRef]

42. Tao, J.-H.; Duan, J.-A.; Jiang, S.; Guo, J.-M.; Qian, Y.-Y.; Qian, D.-W. Simultaneous determination of six short-chain fatty acids in colonic contents of colitis mice after oral administration of polysaccharides from Chrysanthemum morifolium Ramat by gas chromatography with flame ionization detector. J. Chromatogr. B 2016, 1029, 88-94. [CrossRef]

43. Yu, A.I.; Zhao, L.; Eaton, K.A.; Ho, S.; Chen, J.; Poe, S.; Becker, J.; Gonzalez, A.; McKinstry, D.; Hasso, M.; et al. Gut Microbiota Modulate CD8 T Cell Responses to Influence Colitis-Associated Tumorigenesis. Cell Rep. 2020, 31, 107471. [CrossRef]

44. Kim, D.; Langmead, B.; Salzberg, S.L. HISAT: A fast spliced aligner with low memory requirements. Nat. Methods 2015, 12, 357-360. [CrossRef] [PubMed]

45. Yang, J.; Xu, Y.; Yan, Y.; Li, W.; Zhao, L.; Dai, Q.; Li, Y.; Li, S.; Zhong, J.; Cao, R.; et al. Small Molecule Inhibitor of ATPase Activity of HSP70 as a Broad-Spectrum Inhibitor against Flavivirus Infections. ACS Infect. Dis. 2020, 6, 832-843. [CrossRef] [PubMed]

46. Pertea, M.; Pertea, G.M.; Antonescu, C.M.; Chang, T.-C.; Mendell, J.T.; Salzberg, S.L. StringTie enables improved reconstruction of a transcriptome from RNA-seq reads. Nat. Biotechnol. 2015, 33, 290-295. [CrossRef] [PubMed]

47. Langfelder, P.; Horvath, S. WGCNA: An R package for weighted correlation network analysis. BMC Bioinform. 2008, 9, 1-13. [CrossRef]

48. Zhao, X.; Zhu, H.; Chen, J.; Ao, Q. Ftir, xrd and sem analysis of ginger powders with different size. J. Food Process. Pres. 2015, 39, 2017-2026. [CrossRef]

49. Zhao, X.; Liu, H.; Zhang, X.; Ao, Q. Effect of pressure grinding technology on the physicochemical and antioxidant properties of Tremella aurantialba powder. J. Food Process. Pres. 2018, 42, e13833. [CrossRef]

50. Hashim, N.H.N.; Ali, A.H.; Khatib, A.; Latip, J. Discrimination of Clinacanthus nutans extracts and correlation with antiplasmodial activity using ATR-FTIR fingerprinting. Vib. Spectrosc 2019, 104, 102966. [CrossRef]

51. Simpson, E.H. Measurement of diversity. Nature 1949, 163, 688. [CrossRef] 
52. Jan, G.; Belzacq, A.S.; Haouzi, D.; Rouault, A.; Metivier, D.; Kroemer, G.; Brenner, C. Propionibacteria induce apoptosis of colorectal carcinoma cells via short-chain fatty acids acting on mitochondria. Cell Death Differ. 2002, 9, 179-188. [CrossRef]

53. Gabra, M.B.I.; Yang, Y.; Li, H.; Senapati, P.; Hanse, E.A.; Lowman, X.H.; Tran, T.Q.; Zhang, L.; Doan, L.T.; Xu, X.; et al. Dietary glutamine supplementation suppresses epigenetically-activated oncogenic pathways to inhibit melanoma tumour growth. Nat. Commun. 2020, 11, 1-15. [CrossRef]

54. He, Y.; Fu, L.; Li, Y.; Wang, W.; Gong, M.; Zhang, J.; Dong, X.; Huang, J.; Wang, Q.; Mackay, C.R.; et al. Gut microbial metabolites facilitate anticancer therapy efficacy by modulating cytotoxic CD8+ Tcell immunity. Cell Metab. 2021. [CrossRef] [PubMed]

55. Lu, H.; Gui, Y.; Guo, T.; Wang, Q.; Liu, X. Effect of the particle size of cellulose from sweet potato residues on lipid metabolism and cecal conditions in ovariectomized rats. Food Funct. 2015, 6, 1185-1193. [CrossRef]

56. Tuncil, Y.E.; Thakkar, R.D.; Marcia, A.D.R.; Hamaker, B.R.; Lindemann, S.R. Divergent short-chain fatty acid production and succession of colonic microbiota arise in fermentation of variously-sized wheat bran fractions. Sci. Rep. 2018, 8. [CrossRef]

57. Lu, M.; Yan, L.; Wang, B.; Tian, S. Effect of vibrating-type ultrafine grinding on the physicochemical and antioxidant properties of Turkish galls in Uyghur medicine. Powder. Technol. 2018, 339, 560-568. [CrossRef]

58. Oh, J.K.; Yegin, Y.; Yang, F.; Zhang, M.; Li, J.; Huang, S.; Verkhoturov, S.V.; Schweikert, E.A.; Perez-Lewis, K.; Scholar, E.A.; et al. The influence of surface chemistry on the kinetics and thermodynamics of bacterial adhesion. Sci. Rep. 2018, 8. [CrossRef] [PubMed]

59. Boks, N.P.; Norde, W.; van der Mei, H.C.; Busscher, H.J. Forces involved in bacterial adhesion to hydrophilic and hydrophobic surfaces. Microbiol-Sgm 2008, 154, 3122-3133. [CrossRef]

60. Tegoulia, V.A.; Cooper, S.L. Staphylococcus aureus adhesion to self-assembled monolayers: Effect of surface chemistry and fibrinogen presence. Colloid. Surf. B 2002, 24, 217-228. [CrossRef]

61. Parreira, P.; Magalhaes, A.; Goncalves, I.C.; Gomes, J.; Vidal, R.; Reis, C.A.; Leckband, D.E.; Martins, M.C.L. Effect of surface chemistry on bacterial adhesion, viability, and morphology. J. Biomed. Mater. Res. Part A 2011, 99A, 344-353. [CrossRef]

62. Redman, J.A.; Walker, S.L.; Elimelech, M. Bacterial adhesion and transport in porous media: Role of the secondary energy minimum. Environ. Sci. Technol. 2004, 38, 1777-1785. [CrossRef] [PubMed]

63. Sender, R.; Fuchs, S.; Milo, R. Are We Really Vastly Outnumbered? Revisiting the Ratio of Bacterial to Host Cells in Humans. Cell 2016, 164, 337-340. [CrossRef]

64. Manichanh, C.; Borruel, N.; Casellas, F.; Guarner, F. The gut microbiota in IBD. Nat. Rev. Gastroenterol. Hepatol. 2012, 9, 599-608. [CrossRef]

65. Louis, P.; Young, P.; Holtrop, G.; Flint, H.J. Diversity of human colonic butyrate-producing bacteria revealed by analysis of the butyryl-CoA:acetate CoA-transferase gene. Environ. Microbiol. 2010, 12, 304-314. [CrossRef]

66. Cani, P.D.; Van Hul, M.; Lefort, C.; Depommier, C.; Rastelli, M.; Everard, A. Microbial regulation of organismal energy homeostasis. Nat. Metab. 2019, 1, 34-46. [CrossRef] [PubMed]

67. Cuervo, A.; Salazar, N.; Ruas-Madiedo, P.; Gueimonde, M.; Gonzalez, S. Fiber from a regular diet is directly associated with fecal short-chain fatty acid concentrations in the elderly. Nutr. Res. 2013, 33, 811-816. [CrossRef]

68. Deehan, E.C.; Yang, C.; Perez-Munoz, M.E.; Nguyen, N.K.; Cheng, C.C.; Triador, L.; Zhang, Z.; Bakal, J.A.; Walter, J. Precision Microbiome Modulation with Discrete Dietary Fiber Structures Directs Short-Chain Fatty Acid Production. Cell Host Microb. 2020, 27, 389-404. [CrossRef]

69. Gill, S.K.; Rossi, M.; Bajka, B.; Whelan, K. Dietary fibre in gastrointestinal health and disease. Nat. Rev. Gastroenterol. Hepatol. 2020, 18, 101-116. [CrossRef] [PubMed]

70. Stewart, M.L.; Slavin, J.L. Particle size and fraction of wheat bran influence short-chain fatty acid production in vitro. Br. J. Nutr. 2009, 102, 1404-1407. [CrossRef] [PubMed]

71. Tomita, Y.; Ikeda, T.; Sakata, S.; Saruwatari, K.; Sato, R.; Iyama, S.; Jodai, T.; Akaike, K.; Ishizuka, S.; Saeki, S.; et al. Association of Probiotic Clostridium butyricum Therapy with Survival and Response to Immune Checkpoint Blockade in Patients with Lung Cancer. Cancer Immunol. Res. 2020, 8, 1236-1242. [CrossRef]

72. Stary, G.; Olive, A.; Radovic-Moreno, A.F.; Gondek, D.; Alvarez, D.; Basto, P.A.; Perro, M.; Vrbanac, V.D.; Tager, A.M.; Shi, J.; et al. A mucosal vaccine against Chlamydia trachomatis generates two waves of protective memory T cells. Science 2015, 348, aaa8205. [CrossRef] [PubMed]

73. Pabst, O. New concepts in the generation and functions of IgA. Nat. Rev. Immunol. 2012, 12, 821-832. [CrossRef] [PubMed]

74. Olson, B.; Li, Y.; Lin, Y.; Liu, E.T.; Patnaik, A. Mouse Models for Cancer Immunotherapy Research. Cancer Discov. 2018, 8, 1358-1365. [CrossRef] [PubMed] 